\title{
Generalized transport costs and index numbers: A geographical analysis of economic and infrastructure fundamentals
}

\author{
Jose L. Zofío, Ana M. Condeço-Melhorado, Andrés Maroto-Sánchez, Javier Gutiérrez
}

\begin{abstract}
We rely on the economic theory approach to index numbers to improve the existing definitions and decompositions of variations in generalized transport costs (GTCs). As a value index, we decompose GTCs into price and quantity indices associated to economic-market-costs and infrastructure variables-distance and time within a network. The methodology allows the accurate identification of the sources of GTCs decline. We illustrate it for the case of road freight transportation in Spain between 1980 and 2007 and at a highly detailed geographical level. Average GTCs weighted by trade flows have decreased by $16.3 \%$, with infrastructure driving that reduction. We find large territorial disparities in GTCs, but also significant geographical clusters where the market and network indices show spatial association.
\end{abstract}

\section{Introduction}

The importance of accessibility from a locational perspective both for firms and individuals is paramount. This is particularly true for both macro and microgeographical analyses regarding the distribution and specialization of economic activity across space, and their associated volumes of trade. Both locational and trade patterns are highly influenced by transport costs, which constitute a prime measure of accessibility to markets. Although the importance of transport costs has been steadily declining in the past decades (Glaeser and Kohlhase, 2003), the world is still quite far from being flat. Given their importance, many studies have been devoted to accurately defining and measuring transport costs and their determinants. Considering different transportation modes and freight cargo, we can highlight several studies measuring transportation costs: Combes and Lafourcade (2005) for the case of road transportation, Ivaldi and McCullough (2007) in train haulage, Hummels et al. (2007) in air delivery, and Tolofari (1986) and Hummels (2007) in maritime shipping. From the point of view of a static cross-section definition, the cost engineering and accounting methodology followed by these studies is thoughtfully and competently executed, enhancing the customary and simpler unit value and value of time indices into a comprehensive generalised transport cost measure. ${ }^{1}$ However, when it comes to define their evolution time, the approach that

\footnotetext{
1 See World Bank (2009) for a detailed summary of these studies. Oum et al. (1992) discusses the alternative concepts of productivity and methods of measurement (including index numbers) in the transport sector. Our approach based on costs represents the dual of the total factor productivity definition that they consider.
} 
they follow does not rely on the formulation of a producer price index consistent within the economic theory framework, which is completely disregarded. It is as though the authors interested in these issues were reluctant to take their static cross-section efforts when studying transport costs to their logical extension to time-series analysis, in order to obtain consistent definitions, measures and calculations within the standard analytical framework represented by index numbers theory. Laying out this framework and its associated time series extension constitutes the main methodological goal of this study.

This somewhat lax attitude towards modelling changes in transport costs has serious consequences: (i) studies on the same transportation mode carried out by researchers at different times and in different countries are not comparable as they use different methodological approaches; (ii) scholarly work has a limited influence in encouraging national statistical agencies to adopt a standard methodology for the compilation and provision of price index series on transport costs on a regular basis; and (iii) the lack of time-series information hampers long term assessments of economic and infrastructure policies and the definition of guidelines associated to their strategic planning. In this context, the first contribution of this study is theoretical, and involves improving the existing methodology to accurately measure the change in transport costs over time within an index number framework and, by doing so, to provide a consistent decomposition of these changes that allows us to determine precisely the effects that both economic and infrastructure determinants have on transport cost variations. We accomplish this goal by adopting Fisher's (1922) formulation for each of the price and quantity indices into which the GTC variation decomposes. Specifically, for the price index we rely on the (normally unobservable) price aggregate corresponding to the Konüs (1924) true cost of producing index, which can be consistently used to recover its associated implicit quantity index by means of the product rule. Adopting this methodology we avoid theoretical and measurement biases that may have important implications when results are normatively used to propose policy guidelines with respect to market regulation and infrastructure policy.

It is now accepted that a transport cost measure must meet several criteria in order to prove useful for analysis. It must be based on information reflecting the specific itinerary, the transport mode, and the nature of the commodity being transported. A measure satisfying these requirements represents a generalized transportation cost, or GTC, which is defined as the minimum cost of transporting a given load of a particular commodity between a specific origin and a destination, considering the economic variables related to the input costs necessary to produce the transportation service (e.g., labour and capital costs), and the physical features of the available transport infrastructure (e.g., network topology). Because the measure depends on all these elements, it can be decomposed so as to identify its different economic (market) and infrastructure (geographical) determinants. Taking this into consideration, and from the empirical perspective, we consistently calculate the variation in GTCs for the case of road freight transportation in Spain between 1980 and 2007, and decompose it into price (economic) and quantity (infrastructure) components. Therefore, the second main contribution of this study is the calculation of the true cost of producing index and its associated quantity index. Our measurement of GTC variations and their sources represents the first application in the transportation literature to consistently apply index number theory to calculate the true change in the cost of producing a transportation service.

Finally, we have selected the road transportation industry to illustrate our methodology because: (i) this mode represented about $70 \%$ of all ton-kms transported in Spain in $2007-90 \%$ of all land transportation including road, railroad and pipeline (MFOM, 2008); and (ii) there are some previous studies to which we can refer and compare our results: particularly, the empirical framework defining GTC in trucking transportation as presented by Combes and Lafourcade (2005) or Teixeira (2006), or the work by Martínez-Zarzoso and Nowak-Lehmann (2006) on GTC determinants. However, comparing our contribution to these studies, we work with a richer database from both an economic and road network perspective. We have collected economic data for individual operating costs at a regional (NUTS 2) and-when available-provincial (NUTS 3 ) level (e.g., labour and fuel costs, which represent over 50\% of the overall costs, differ at the provincial level), allowing us to determine alternative economic cost structures for firms operating in different geographical areas. From a geographical perspective, the road network database includes features that are normally overlooked, such as the degree or steepness of the road sections comprising the arcs, which influence several variables such as actual speed and fuel consumption. As for the nature of the commodity being transported, the proposed methodology allows for commodity specific costs as well as possible restrictions on the use of the road network, both of which condition the optimal least cost routes. Therefore, even if in the empirical section we take as reference vehicle the 40-ton articulated truck, suited for transportation of a wide range of goods (representing about $80 \%$ of road freight transport), the methodology lays the framework to accommodate other types of goods such as hazardous materials, perishable commodities.

The paper is structured as follows. Section 2 presents the theoretical framework based on the economic theory of index numbers by defining the volume index corresponding to GTC variation and its decomposition into the Konüs cost of producing price index and its associated quantity index, related to transport economic costs and network infrastructure respectively. Section 3 starts with a detailed description of the economic (unit-price) and GIS databases used in the calculation of the GTCs for the Spanish road freight transportation industry since 1980 . Here we present the empirical results regarding the GTCs as well as their Konüs price and quantity indices components, and discuss the sources of GTC decline. Using Moran's indicator and Anselin's local indicator, in Section 4 we explore the existence of significant geographical clusters where the variations in GTCs and their economic and infrastructure components exhibit significant patterns of spatial association. In this section we also calculate several inequality measures to determine whether the steady decline in all the indices has been characterized by a convergence process, thereby reducing territorial disparities in terms of GTCs, economic costs, and accessibility. Finally, Section 5 concludes with relevant policy implications and final remarks. 


\section{Index number methods and generalized transport costs}

\subsection{Generalized distance and time related transport costs}

Nichols (1975) introduced the concept of generalized transport cost depending on distance and time as the key accessibility variables to which economic costs (unit prices) are associated, while Combes and Lafourcade (2005) provide its most comprehensive characterization for the case of road freight transportation. ${ }^{2}$ Here we expand their notation so as to introduce the index number methodology, and denote by $G T C_{i j, c}^{t, t}$ the generalized transport cost between an origin $i$ and a destination $j$ for commodity $c$, considering its associated economic costs and infrastructure existing in period $t$ (first and second superscripts, respectively), corresponding to the cheapest itinerary $I_{i j, c}^{t, t^{*}}$ among the set of possible itineraries $I_{i j, c}^{t}$, and considering both the distance and time accessibility variables. Economics costs depend on the type of commodity as the reference vehicle, insurance premiums, qualification of the driver, etc., as well as legal restrictions both in driving times (e.g., more frequent and longer mandatory stops for hazardous materials) and the use of the road network, (e.g., urban areas), result in substantial differences in operating costs. The itineraries are comprised of different arcs $a_{c}$, with an associated set of physical and legal attributes (depending on the type of commodity) in period $t, \mathbf{x}_{a_{c}}^{t}$. The primary physical attributes of an arc are its distance, $d_{a}^{t}$, road type, $r_{a}^{t}$, and gradient (steepness), $g_{a}^{t}$. The arc speed, $s_{a_{c}}^{t}$, can be determined from these last two (representing the actual speed-e.g. in case of congestion or very steep roads-or maximum legal speed given the road type $r$ and commodity $c$, e.g., wide loads), and from there we can determine the time it takes to cover it, $t_{a_{c}}^{t}=d_{a}^{t} / s_{a_{c}}^{t}$. As a result the physical characteristics of an arc are ultimately summarized by its associated distance and time variables: $d_{a}^{t}$ and $t_{a_{c}}^{t}$. The legal attributes $l_{a_{c}}^{t}$ correspond to restrictions on the type of vehicle (e.g., longer and heavier vehicles-megatrucks), the movement of certain goods (e.g., hazardous materials), etc.

The economic distance unit costs (prices) in time $t$ for a specific type of commodity $c$, denoted by $e_{k, c}^{t}$, i.e., Euro per kilometre, include the following variables, $k=1, \ldots, 5:^{3}$ (i) fuel costs: fuel $t_{i, c}^{t}$, which are associated with each arc given its road type: $r_{a}^{t}$, gradient: $g_{a}^{t}$, and speed: $s_{a_{c}}^{t}$ (fuel costs are computed by multiplying the fuel price (Euro per litre) by the fuel consumption of its particular arc); (ii) toll costs: tollt t, , that result from multiplying the unit cost (Euro cents/km) by the length of the arc $d_{a}^{t}$; (iii) accommodation and allowance costs: accomsallow $w_{c}^{t}$; (iv) tire costs: tire $t_{c}^{t}$, and, (v) vehicle maintenance and repair costs: repEmant $c_{c}^{t}$. Taking into account these operating costs, the total distance cost is:

$$
\operatorname{DistC}_{i j, c}^{t, t}=\sum_{a \in I_{i, c}^{t}}\left(\sum_{k} e_{k, c}^{t}\right) d_{a}^{t}=\sum_{a \in l_{i, c}^{t}}\left(\text { fuel }_{i, c, a(r, t)}^{t}+\text { toll }_{i, c, a(r=1, t)}^{t}+\operatorname{accom\& allow}_{c}^{t}+\text { tire }_{c}^{t}+\text { rep\&mant }_{c}^{t}\right) d_{a}^{t}
$$

Likewise, the economic unit costs (prices) associated to time for a specific type of commodity $c$, denoted by $e_{l, c}^{t}$, i.e., Euro per hour, include the following $l=1, \ldots, 6$ variables: (i) labour cost associated with gross salaries: lab $b_{i, c}^{t}$, including social security payments; (ii) financial costs associated to amortization: $\operatorname{amort}_{c}^{t}$; and (iii) vehicle financing: fin $_{i, c}^{t}$, assuming that it remains operative only for a certain number of hours/year (according to its technical characteristics and other institutional issues, for example, driving and resting times); (iv) insurance costs, ins $s_{c}^{t}$; (v) taxes: tax $t_{i, c}^{t}$ (including central, regional -state-, provincial -county-, and municipal -city- government taxes); and finally (vi) indirect costs: ind $d_{i, c}^{t}$, associated to other administration overheads (offices and other technical equipment), operating expenses (administrative employment) and commercial costs (outsourcing activities and marketing).

Given the driving time for an arc: $t_{a_{c}}^{t}=d_{a}^{t} / s_{a_{c}}^{t}$, the economic time costs in period $t$, and the existing road infrastructure in $t$, the overall cost associated to travelling the whole length of an itinerary is:

$$
\operatorname{TimeC}_{i,, c}^{t, t}=\left(\sum_{l} e_{l, c}^{t}\right)\left(\sum_{a \in l_{i, c}^{t}} t_{a_{c}}^{t}\right)=\left(\sum_{l} e_{l, c}^{t}\right)\left(\sum_{a \in \epsilon_{i, c}^{t}} \frac{d_{a}^{t}}{S_{a_{c}}^{t}}\right)=\left(\operatorname{lab} b_{i, c}^{t}+\operatorname{amort}_{c}^{t}+f i n_{c}^{t}+i n s_{c}^{t}+\operatorname{tax} x_{i, c}^{t}+i n d_{i, c}^{t}\right)\left(\sum_{a \in l_{i, c}^{t}} \frac{d_{a}^{t}}{s_{a_{c}}^{t}}\right) .
$$

We assume that a transport firm minimizes the cost of producing the transportation service subject to the existing vehicle technology and any additional legal restrictions on the use of the road network as a result of specific regulations (e.g., hazardous materials). This minimum cost corresponds to the solution of the following problem that finds the least cost route $I_{i j}^{t, t^{*}}$ among the set of itineraries $I_{i j}^{t}$ :

$$
\operatorname{GTC}_{i j, c}^{t, t}=\min _{I_{i, j, c}^{t, t} \in l_{i, c}^{t}}\left(\operatorname{DistC}_{i j, c}^{t}+\operatorname{TimeC}_{i j, c}^{t}\right)=\sum_{a \in t_{i, c}^{t}}\left(\sum_{k} e_{k, c}^{t}\right) d_{a}^{t, t^{*}}+\left(\sum_{l} e_{l, c}^{t}\right)\left(\sum_{a_{c} \in l_{i, c}^{t}} t_{a_{c}}^{t, t^{*}}\right)
$$

where the optimal distance and time variables solving (3) correspond to

$$
d_{i j, c}^{t, t^{*}}=\sum_{a \in I_{i, c}^{t}} d_{a}^{t, t^{*}} \text { and } t_{i j, c}^{t, t^{*}}=\sum_{a \in l_{i j}^{t}} t_{a_{c}}^{t, t^{*}} .
$$

\footnotetext{
${ }^{2}$ For a review of GTCs and other accessibility and market potential measures, see Geurs and Ritsema van Eck (2001). Also for a thoughtful presentation on distance and time as factors of competitiveness of intermodal transport, see Kreutzber (2008).

${ }^{3}$ Subscript $i$ indicates that the reference cost is available for the particular region or province where arc $a$ is located.
} 
Levels and variations in unit economic transport costs, 1980-2007. ' Source: Authors' compilation.

\begin{tabular}{|c|c|c|c|c|c|c|c|}
\hline & \multicolumn{2}{|c|}{ Levels (Euros) } & \multicolumn{2}{|c|}{ Share in total costs (\%) } & \multirow{2}{*}{$\begin{array}{l}\text { Unweighted variation (\%) } \\
\Delta 07 / 80 \\
\text { (5) }\end{array}$} & \multicolumn{2}{|c|}{ Weighted variation (\%) } \\
\hline & $\begin{array}{l}1980 \\
(1)\end{array}$ & $\begin{array}{l}2007 \\
(2)\end{array}$ & $\begin{array}{l}1980 \\
(3)\end{array}$ & $\begin{array}{l}2007 \\
(4)\end{array}$ & & $\begin{array}{l}\Delta 07 / 80^{c} \\
(6)=(3) \cdot(4)\end{array}$ & $(7)$ \\
\hline Direct costs $(\mathrm{km})$ & 1.13 & 0.94 & 91.84 & 91.69 & -16.25 & -14.92 & 92.62 \\
\hline Distance costs (km) & 0.51 & 0.52 & 41.48 & 50.48 & 2.09 & 0.87 & -5.38 \\
\hline Fuel & 0.22 & 0.30 & 18.28 & 29.04 & 33.25 & 6.08 & -37.74 \\
\hline Accom.\&allow. & 0.13 & 0.11 & 10.50 & 10.87 & -13.16 & -1.38 & 8.58 \\
\hline Tire & 0.08 & 0.05 & 7.12 & 4.92 & -42.07 & -3.00 & 18.60 \\
\hline Maint.\&repair. & 0.04 & 0.04 & 3.59 & 4.24 & -1.02 & -0.04 & 0.23 \\
\hline Toll $^{\mathrm{d}}$ & 0.02 & 0.01 & 1.98 & 1.41 & -40.36 & -0.80 & 4.95 \\
\hline Time costs $(\mathrm{h})$ & 29.28 & 26.80 & 50.36 & 41.22 & -8.46 & -15.79 & 98.00 \\
\hline Capital & 10.34 & 8.56 & 17.78 & 13.16 & -17.22 & -6.74 & 41.85 \\
\hline Amortization & 7.19 & 7.13 & 12.36 & 10.96 & -0.81 & -3.17 & 19.65 \\
\hline Financing & 3.15 & 1.43 & 5.42 & 2.20 & -54.64 & -3.58 & 22.20 \\
\hline Operating & 18.94 & 18.25 & 32.58 & 28.06 & -3.68 & -9.04 & 56.14 \\
\hline Labour & 12.61 & 14.36 & 21.69 & 22.09 & 13.90 & -3.16 & 19.62 \\
\hline Insurance & 5.92 & 3.41 & 10.18 & 5.24 & -42.39 & -5.78 & 35.89 \\
\hline Taxes & 0.41 & 0.47 & 0.71 & 0.73 & 14.28 & -0.10 & 0.63 \\
\hline Indirect cost (km) & 0.10 & 0.08 & 8.16 & 8.31 & -14.57 & -1.19 & 7.38 \\
\hline Economic costs $(\mathrm{km})^{\mathrm{b}}$ & 1.23 & 1.03 & 100.00 & 100.00 & -16.11 & -16.11 & 100.00 \\
\hline
\end{tabular}

Note: Annual distance driven of the representative 40t. articulated truck increased from 90,000 km in 1980 to $120,000 \mathrm{~km}$ in 2007 , while the number of total annual hours driven remained stable at 1906 over the whole period.

Totals and subtotals in bold.

a Variation of unit economic costs in constant 2007 Euros.

b Economic costs per unit distance ( $\mathrm{km}$ ), one-time costs (per hour) are converted to distance costs by dividing by the average speed: Economic costs/ $\mathrm{km}=$ Distance costs $/ \mathrm{km}+$ Time costs $/ \mathrm{h} . \div$ speed $(\mathrm{km} / \mathrm{h}$. $)$.

c Shift-share variation. Unit cost variation weighted by their 1980 cost share in total economic costs. This corresponds to the national average of the Laspeyres index $E C_{i j}^{L}(\%)$. Column (7) shows the contribution of each cost category to the overall variation, i.e. direct costs contribute $92.62(\%)=-14.92(\%) /$ $16.11(\%)$.

d The toll cost is an average cost for the reference vehicle assuming that $10 \%$ of the annual distance corresponds to this category. However, GTC calculations consider actual tolls of the arcs really used.

The definition of the economic and time costs in Eqs. (1) and (2), constituting the arguments of the GTC minimizing function (3), are closely related to the existing Unit Value (UV) and Value of Time (VoT) indices, which provide for an specific commodity the cost of transporting it taking into account a wide range of characteristics that are comparable to those considered here, defining distance and time cost in terms of Euro per kilometre and Euro per hour. In the empirical Section 3.1 (Table 1) we provide a specific example of the methodology followed by the Spanish Ministerio de Fomento to compile such indices. Finally, we must remark should that from the economic theory approach to index numbers, these optimal accessibility values depend on economic costs, and therefore $d_{i j, c}^{t, t^{*}}$ and $t_{i j, c}^{t, t^{*}}$ will not normally coincide with the shortest or fastest itineraries, i.e., minimum real distance and minimum real time, which are the solutions to conventional best route problems that do not consider economic costs (e.g., as in portable GPS devices).

\subsection{Generalized transport cost variation and its decomposition}

Since $G T C_{i j, c}^{t, t}$ is the outcome of an optimizing behaviour by firms which minimizes the transport cost between $i$ and $j$ for commodity $c$, it is natural to resort to the economic theory of index numbers (Diewert, 1993; Fisher and Shell, 1998) when defining the variation in $G T C_{i j, c}^{t, t}$ between a base period $t=0$ and the current period $t=1 .{ }^{4}$ This approach assumes that given the unit prices relating to distance and time incurred by the transportation firm in period $t$, the choice of the optimal itinerary based on the optimal distance and time quantities is the solution to the cost minimizing problem. From this perspective the firm demands the specific arcs comprised in the optimal itinerary, and the road network can be thought of as the available infrastructure-technology-to produce the transportation service. As a result, when dealing with GTCs, we assume that the set of economic unit prices $\left(e_{k, c}^{t}, e_{l, c}^{t}\right)$ and accessibility quantity variables $\left(d_{i j, c}^{t, t^{*}}, t_{i, j, c}^{t, t^{*}}\right)$ in the base and current periods are interdependent, since the firm demands the optimal itinerary given those prices (as opposed to the axiomatic approach to index numbers that assumes that both sets of variables are independent). With this in mind, the variation in GTC tij,c between two consecutive periods is defined through the following value aggregate index that compares the costs of the transportation service in both periods:

$$
\Delta G T C_{i j, c}^{0,1}=\frac{\operatorname{GTC}_{i j, c}^{1,1}}{\operatorname{GTC}_{i j, c}^{0,0}}=\frac{\min _{l_{i, j, c}^{1,1^{*}} \in \in_{i, c}^{1, c}}\left(\operatorname{DistC}_{i j, c}^{1,1}+\operatorname{TimeC}_{i j, c}^{1,1}\right)}{\min _{I_{i, j, c}^{0,0^{*}} \in l_{i, c}^{0}}\left(\operatorname{DistC}_{i, j, c}^{0,0}+\operatorname{TimeC}_{i j, c}^{0,0}\right)} .
$$

\footnotetext{
${ }^{4}$ See also IMF (2004) for a presentation of the index numbers in a production-cost function context. Diewert (2004) reviews the present and future perspectives of research on index numbers.
} 
As this index incorporates information relating to the change in both cost (economic) and physical (infrastructure) aspects, the problem is how to decompose it in a sensitive manner so as to identify the contribution that each one of these elements makes to the variation in GTC. This results in a price index which comprises the change in the distance $e_{k, c}^{t}$, and time $e_{l, c}^{t}$, economic unit prices; and its counterpart quantity index representing the change in the optimal distance $d_{i j, c}^{t, t^{*}}$, and time $t_{i j, c}^{t, t^{*}}$, accessibility variables.

\subsubsection{Price and quantity indices}

To reveal the sources that give rise to these variations we use the Konüs (1924) true cost of producing index, which at our current setting allows the comparison between the minimum cost of linking the origin $i$ and destination $j$ considering the unit prices corresponding to the base and current periods, but using the same network infrastructure. Considering the base period $t=0$ as reference, the LaspeyresKonüs cost of producing price index capturing the change in the economic variables corresponds to:

$$
E C_{i j, c}^{0}=\frac{G T C_{i j, c}^{1,0}}{G T C_{i j, c}^{0,0}}=\frac{\min _{I_{i j, c}^{1,0^{*}} \in I_{i j, c}^{0}}\left(\operatorname{DistC}_{i j, c}^{1,0}+\operatorname{TimeC}_{i j, c}^{1,0}\right)}{\min _{I_{i j, c}^{0,0^{*}} \in I_{i j, c}^{0}}\left(\operatorname{Dist} C_{i, c}^{0,0}+\operatorname{TimeC}_{i j, c}^{0,0}\right)},
$$

where the denominator corresponds to (3), but the numerator represents a hypothetical generalized transport cost: $G T C_{i j, c}^{1,0}$, involving the calculation of the cost the transportation firm would incur given the distance and time unit prices in the current period: $e_{k, c}^{1}$ and $e_{l, c}^{1}$, and the network infrastructure existing in the base period, i.e.,

$$
G T C_{i j, c}^{1,0}=\min _{I_{i j, c}^{1,0^{*}} \in I_{i j, c}^{0}}\left(\operatorname{DistC}_{i j, c}^{1,0}+\operatorname{TimeC}_{i j, c}^{1,0}\right)=\sum_{a \in I_{i j, c}^{0}}\left(\sum_{k} e_{k, c}^{1}\right) d_{a}^{1,0^{*}}+\left(\sum_{l} e_{l, c}^{1}\right)\left(\sum_{a_{c} \in I_{i j, c}^{0}} t_{a_{c}}^{1,0^{*}}\right) .
$$

If $E C_{i j, c}^{0}<1$, there is a deflationary process. Conversely, $E C_{i j, c}^{0}>1$ indicates an increase in economic costs, whereas $E C_{i j, c}^{0}=1$ signals that there is no variation in the aggregate costs between the base and current periods. We note on the one hand that the optimal distances and times corresponding to the cheapest itineraries may not coincide in both periods. In that case $I_{i j, c}^{0,0^{*}} \neq I_{i j, c}^{1,0^{*}}$ with $d_{i j, c}^{0,0^{*}}=\sum_{a \in I_{i, c}^{t}} d_{a}^{0,0^{*}} \neq d_{i j, c}^{1,0^{*}}=\sum_{a \in I_{i j, c}^{t}} d_{a}^{1,0^{*}}$ and $t_{i j, c}^{0,0^{*}}=\sum_{a_{c} \in I_{i j, c}^{t}} t_{a_{c}}^{0,0^{*}} \neq t_{i j, c}^{1,0^{*}}=\sum_{a_{c} \in I_{i j, c}^{t}} t_{a_{c}}^{1,0^{*}}$. It is clear that a change in the unit prices could result in a change in the optimal itinerary for the firm, which may opt for an alternative route, e.g., if the price of toll highways in the current period decreases with respect to the remaining unit prices, the firm may demand a toll arc that was not demanded with the base period prices. On the other hand, if the minimum cost itinerary does not vary from the base to the current period: $I_{i j, c}^{0,0^{*}}=I_{i j, c}^{1,0^{*}}$, then the distance and time quantities do not change; and the price index (5) corresponds precisely to the familiar Laspeyres (1871) formulation that uses the base period quantities as a reference for the price change: $E C_{i j, c}^{0}=E C_{i j, c}^{L}$.

Since our goal is to decompose the variation of the generalized transport costs $\triangle G T C_{i j, c}^{0,1}$ into a price index and a quantity index, once we have $E C_{i j, c}^{0}$ we can recover its associated Paasche-Konüs implicit quantity index because it is completely determined by means of the product rule. Denoting this infrastructure change index by $I C_{i j, c}^{1}$, we have:

$$
\Delta G T C_{i j, c}^{0,1}=\frac{G T C_{i j, c}^{1,1}}{G T C_{i j, c}^{0,0}}=E C_{i j, c}^{0} \cdot I C_{i j, c}^{1}=\frac{G T C_{i j, c}^{1,0}}{G T C_{i j, c}^{0,0}} \cdot I C_{i j, c}^{1},
$$

and therefore:

$$
I C_{i j, c}^{1}=\Delta G T C_{i j, c}^{0,1} / E C_{i j, c}^{0}=\frac{G T C_{i j, c}^{1,1}}{G T C_{i j, c}^{0,0}} / \frac{G T C_{i j, c}^{1,0}}{G T C_{i j, c}^{0,0}}=\frac{G T C_{i j, c}^{1,1}}{G T C_{i j, c}^{1,0}}=\frac{\min _{I_{i j, c}^{1,1^{*}} \in \mathrm{I}_{i j, c}^{1}}\left(\operatorname{DistC}_{i j, c}^{1,1}+\operatorname{TimeC}_{i j, c}^{1,1}\right)}{\min _{I_{i j, c}^{1,0^{*}} \in \mathrm{I}_{i j, c}^{0}}\left(\operatorname{DistC}_{i j, c}^{1,0}+\operatorname{TimeC}_{i j, c}^{1,0}\right)} .
$$

The $I C_{i j, c}^{1}$ index reflects the change in the aggregate quantity variables using the current period unit prices as a reference by updating the infrastructure network. As the counterpart to $E C_{i j . c}^{0}$, (8) can be regarded as the associated (input-oriented) quantity index measuring productivity growth as the aggregate reduction in the distance and time accessibility variables brought about by changes in the infrastructure network. It is normally expected that $I C_{i j, c}^{1}<1$, showing that this term contributes to a reduction in GTC as a result of improvements in the transportation network, thereby reducing both the optimal distance and time from the base to the current period. Conversely, $I C_{i j, c}^{1}>1$ would indicate an increase in transport costs, caused by deterioration in the infrastructures (lack of maintenance, wars, ...). Finally, a value of $I C_{i j, c}^{1}=1$ would be obtained when changes in the infrastructure network do not produce any change in the optimal itineraries, i.e., $I_{i j, c}^{1,1^{*}}=1 I_{i j, c}^{1,0^{*}}$, and therefore $E C_{i j, c}^{0}=\Delta G T C_{i j, c}^{0,1}$.

We can now recall the departure point in our previous analysis corresponding to the price index (5) and define the analogous PaascheKonüs cost of producing price index which considers the reference network infrastructure to be the one existing in the current period $t=1$. In this case, we define the index $E C_{i j, c}^{1}=G T C_{i j, c}^{1,1} / G T C_{i j, c}^{0,1}=\min _{I_{i j, c}^{1,1^{*}} \in I_{i j, c}^{1}}\left(\operatorname{DistC}_{i j, c}^{1,1}+\operatorname{Time}_{i j, c}^{1,1}\right) /$ 


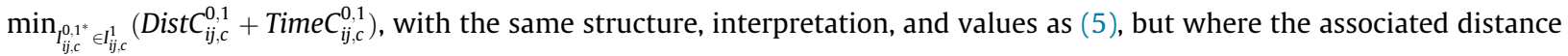
and time costs: Dist $_{i j, c}^{0,1}$ and Time $_{i j, c}^{0,1}$, reverse the reference periods for the economic unit prices and the accessibility quantity variables associated to the network infrastructure. On this occasion, if the optimal itinerary within the current period network remains constant regardless of changes in unit prices, then $I_{i j, c}^{1,1^{*}}=I_{i j, c}^{0,1^{*}}$ and $E C_{i j, c}^{1}$ adopts the form of the Paasche (1874) price index: $E C_{i j, c}^{1}=E C_{i j, c}^{p}$. Konüs (1924) shows that the Laspeyres and Paasche price indices respectively represent a lower and upper bound to the true index. Given this price index, the counterpart decomposition to (7) is $\Delta G T C_{i j, c}^{0,1}=G T C_{i j, c}^{1,1} / G T C_{i j, c}^{0,0}=E C_{i j, c}^{1} \cdot I C_{i j, c}^{0}=\left(G T C_{i j, c}^{1,1} / G T C_{i j, c}^{0,1}\right) \cdot I C_{i j, c}^{0}$, allowing us to recover its corresponding Laspeyres-Konüs implicit quantity index, which uses the base period prices as a reference, thereby obtaining

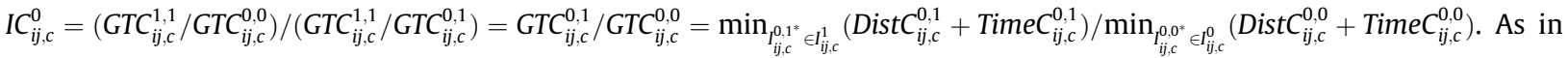
the previous $I C_{i j, c}^{1}$ case, when the changes in the infrastructure network do not alter the choice of optimal itinerary, i.e., $I_{i j, c}^{0,1^{*}}=I_{i j, c}^{0,0^{*}}, I C_{i j, c}^{0}=1$, and $E C_{i j, c}^{1}=\Delta G T C_{i j, c}^{0,1}$.

\subsubsection{The Fisher-type version of GTC variation and the transitivity property}

These results show that there are two alternative ways of decomposing the variation in GTC, depending on the choice of the price and its associated quantity indices, i.e. $\Delta G T C_{i, c}^{0,1}=G T C_{i j, c}^{1,1} / G T C_{i, c, c}^{0,0}=E C_{i j, c}^{0} \cdot I C_{i j, c}^{1}=E C_{i j, c}^{1} \cdot I C_{i j, c}^{0}$. In fact, depending on the alternative reference periods for the economic and infrastructure indices, we would generally obtain two different values for the contribution of economic prices and accessibility quantities. This suggests the following geometric mean decomposition of $\triangle G T C_{i j, c}^{0,1}$, which does not settle for one particular period, but takes them both into account in a symmetrical way (in case that the price and quantity indices were equal to their Laspeyres and Paasche counterparts the formulation would correspond exactly to the Fisher expression):

$$
\Delta G T C_{i j, c}^{0,1}=G T C_{i j, c}^{1,1} / G T C_{i j, c}^{0,0}=\left[\left(E C_{i j, c}^{0} \cdot I C_{i j, c}^{1}\right) \cdot\left(E C_{i j, c}^{1} \cdot I C_{i j, c}^{0}\right]^{1 / 2}=\left(E C_{i j, c}^{0} \cdot E C_{i j, c}^{1}\right)^{1 / 2}\left(I C_{i j, c}^{0} \cdot I C_{i j, c}^{1}\right)^{1 / 2}=E C_{i j, c}^{0,1} \cdot I C_{i j, c}^{0,1} .\right.
$$

We end this theoretical section by recalling the axiomatic approach to index numbers, and highlight one relevant property of these indices that proves useful in a time series context such as we undertake in the empirical section. An index is said to verify the transitivity property (or circularity test) if it is possible to consistently decompose its time variations from an initial to a final period into consecutive subperiods, thereby allowing for specific time analyses. These might include, for example, time periods where there have been major investment efforts resulting in improvements in the transportation network, which should translate into larger GTC reductions, or price inflationary periods that would have the opposite effect due to an increase in the price index. All previous indices satisfy the transitivity property and, therefore, given a sequence of periods: $t=0,1,2$, it is verified that $\Delta C G T_{i j, c}^{0,2}=\Delta C G T_{i j, c}^{0,1} \cdot \Delta C G T_{i j, c}^{1,2}$. Focusing on the initial definition (4) and the decomposition presented in (9) we see that, given a sequence of $T$ periods, $t=0, \ldots T$, it is possible to decompose the variation in GTC between the first and last periods into any subperiod using any of the available alternatives:

$$
\begin{aligned}
\Delta C G T_{i j, c}^{0, T} & =\frac{C G T_{i j, c}^{T, T}}{C G T_{i j, c}^{0,0}}=\Delta C G T_{i j, c}^{0, t} \cdot \Delta C G T_{i j, c}^{t, T}=\frac{C G T_{i j, c}^{t, t}}{C G T_{i j, c}^{0,0}} \cdot \frac{C G T_{i j, c}^{T, T}}{C G T_{i j, c}^{t, t}}=\left(E C_{i j, c}^{0} \cdot I C_{i j, c}^{t}\right)\left(E C_{i j, c}^{t} \cdot I C_{i j, c}^{T}\right)=\left(E C_{i j, c}^{t} \cdot I C_{i j, c}^{0}\right)\left(E C_{i j, c}^{T} \cdot I C_{i j, c}^{t}\right) \\
& =\left[\left(E C_{i j, c}^{0} \cdot E C_{i j, c}^{t}\right)^{1 / 2}\left(I C_{i j, c}^{0} \cdot I C_{i j, c}^{t}\right)^{1 / 2}\right]\left[\left(E C_{i j, c}^{t} \cdot E C_{i j, c}^{T}\right)^{1 / 2}\left(I C_{i j, c}^{t} \cdot I C_{i j, c}^{T}\right)^{1 / 2}\right]=\left(E C_{i j, c}^{0, t} \cdot I C_{i j, c}^{0, t}\right)\left(E C_{i j, c}^{t, T} \cdot I C_{i j, c}^{t, t}\right) .
\end{aligned}
$$

From this expression we can recover any change in the generalized transport cost between an intermediate period and the final year by dividing the fixed base indices corresponding to those periods, i.e.,

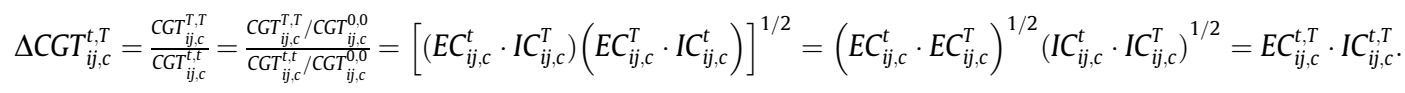

That is, we can recover the chain component $\Delta C G T_{i j, c}^{t, T}$ of the variation in GTC that verifies the transitivity property for the whole period: $\Delta C G T_{i j, c}^{0, T}=\Delta C G T_{i j, c}^{0, t} \cdot \Delta C G T_{i j, c}^{t, T}$. Moreover, as these expressions can be generalized to any two particular subperiods, we can also calculate the cumulative variation-chained components-of the generalized transport costs between period $t$ and $t+n$, whose particular definition is ( $n=1$ would give the year by year variations):

$$
\Delta C G T_{i j, c}^{t, t+n}=\frac{C G_{i j, c}^{t+n, t+n}}{C G T_{i, c}^{t, t}}=\frac{C G_{i, c}^{t+n, t+n} / C G T_{i j, c}^{0,0}}{C G T_{i, c}^{t, t} / C G T_{i j, c}^{0,0}}=\left[\left(E C_{i j, c}^{t} \cdot I C_{i j, c}^{t+n}\right)\left(E C_{i j, c}^{t+n} \cdot I C_{i j, c}^{t}\right]^{1 / 2}=\left(E C_{i j, c}^{t} \cdot E C_{i j, c}^{t+n}\right)^{1 / 2}\left(I C_{i j, c}^{t} \cdot I C_{i j, c}^{t+n}\right)^{1 / 2}=E C_{i j, c}^{t, t+n} \cdot I C_{i j, c}^{t, t+n} .\right.
$$

The above decompositions of variation in GTCs based on the economic theory of index numbers constitutes a substantial advance with respect to other studies on the sources of transport cost variations which do not use the index number theory and its potential when decomposing them, in order to consistently identify their sources. 


\section{GTCs of road freight transportation in Spain (1980-2007)}

\subsection{Calculating GTCs: the economic (unit-price) and GIS (infrastructure) databases}

The reference economic costs used to calculate GTCs are obtained using the engineering approach based on the operating expenses of the most common type of vehicle: the 40-ton articulated truck. High frequency monthly data based on a detailed scrutiny of the accountancy of transport firms is available for this particular vehicle. ${ }^{5}$ Therefore, to reduce notation clutter, in the remaining of the text we drop the subscript $c$ identifying the specific commodity, as it refers to any good suitable to be transported in the standard truck (e.g., palletized cargo). Our methodology, based on these indicators, differentiates between distance and time costs according to the structure presented in Eqs. (1) and (2). Compiling the economic database is an intricate task due to its complexity, the variety of potential alternatives and the lack of data for many components that define the overall and unit costs. All the different economic and technological hypotheses concerning the reference vehicle that are used in this study are reported in Zofío et al.'s (2011) technical Appendixes. They also show the ancillary issues necessary to compute the economic costs during the period 1980-2007 (i.e., the criteria to update the costs). At regional level, the specific values of the economictechnical assumptions may differ for numerous reasons (e.g., in Spain collective bargaining takes place at the provincial level, which results in wage differentials at this geographical level). Finally, current economic variables have been expressed in real terms using the regional GDP deflator in order to obtain real costs. We point out that these reference costs are influenced by institutional, regulatory and legal issues (taxes on fuel, driving and resting times, minimum wages...), as well as the industrial structure (relationship between efficiency and competition, firm size...) that plays also an important role in their behaviour over time. $^{6}$ Therefore, the different components which make up the individual unit-price economic costs depend on multiple factors that are taken into account in the analysis.

Considering all the available information, unit price data for all economic costs have been systematically collected for the Spanish provinces. Table 1 presents information on unit cost variations between 1980 and 2007 at national level (column 5 ). Only two major price categories have increased in real terms during this period. Firstly, fuel costs-accounting for almost one third of the total costs-underwent an accumulated growth of up to 33.3\%. The high inflation experienced in recent years has counterbalanced the technological and efficiency improvements made by vehicle manufacturers after the oil crisis-specifically, new engines consuming as much as a $25.5 \%$ less. Secondly, labour costs-accounting for $13 \%$ of the total costs-have increased by a contained $13.9 \%$ during these years. This is a result of strong competitive pressures that have characterized the Spanish road freight transport industry during recent years, which has kept salary increases moderate. Despite the increase in these two economic costs, the downward behaviour of other categories has resulted in a $16.1 \%$ reduction in total unit costs at constant prices from 1980 to $2007 .{ }^{7}$ From the perspective of the index number methodology, we note that the shift-share analysis presented in the last two columns would correspond to the standard decomposition of a Laspeyres producer price index that would produce a national statistical agency and that weights each unit price variation, i.e., $e_{k}^{07} / e_{k}^{80}$ and $e_{l}^{07} / e_{l}^{80}$, by its corresponding share in the total economic costs, but does not take into account the network infrastructure. This standard version of cost indices that does not consider the optimizing behaviour of transport firms within the road network as the GTCs in (3), are parallel to the Unit Value Indices (UVI) reflecting the change in transport costs associated distance, as well as Value of Time (VoT) indices associated to time. In Table 1, the $2.09 \%$ increase in distance costs and its counterpart $8.46 \%$ reduction in time costs, closely correspond to the UVI and VoT calculations made by national statistical offices, government agencies, or industry associations (e.g., the Spanish Observatory on Freight Road Transportation Costs). This information can be aggregated into a single value reflecting the overall change in economic costs and resulting in a $16.11 \%$ reduction.

Geographic Information System (GIS) techniques have been used to compute minimum cost routes using Dijkstra's (1959) shortest path algorithm. Seven digital road networks have been created corresponding to the following years: 1980, 1985, 1990, 2000, 2005 and 2007. Table 2 summarizes the changes in the different type of roads. The investments efforts to upgrade the network to a high-capacity infrastructure are visible. Highways accounted for $335 \mathrm{~km}$ in 1980 and $9557 \mathrm{~km}$ in 2007, representing a notable increase of $2752 \%$ in 27 years. Tolled roads have grown by $77 \%$ since 1980 . National roads have decreased their length mainly in the first two decades due to a common practice of doubling the existing national roads to upgrade the infrastructure to highways. From the perspective of the network topology, the radial nature of the network was reinforced in first two decades by improving the connections between Madrid and the peripheral regions, while in the last decade the investment efforts were devoted to improve the density of the high-capacity roads corresponding to the non-radial sections of the grid.

\footnotetext{
${ }^{5}$ In the Spanish case the Directorate General of Road Transportation collects monthly statistics on transport costs within the 'Observatory of Road Freight Transportation' (MFOM, 2007).

${ }^{6}$ For example, the road freight transportation sector is atomized in Spain, where $87 \%$ of the firms are small (with fewer than five vehicles). This gives rise to high competitive pressures and greater cost efficiency.

7 For example, Spain's entry into the European Monetary Union resulted in a sharp downturn in interest rates that reduced capital costs significantly, thereby counterbalancing the opposite effect brought about by shorter useful years in the vehicle life-cycle and longer financing years. Other factors such as the modernization and consolidation of insurance markets, technological advances in rethreading and tire manufacturing, and negotiations between toll highway operators and government agents have played a role in this cost reduction. Also, contributing to this overall reduction in total unit costs per kilometre are the technological improvements incorporated into the vehicles which have allowed the annual distance driven to increase by one third, from 90,000 km to $120,000 \mathrm{~km}$.
} 
Table 2

Variation in number and length of arcs (19802007). Source: Authors' compilation.

\begin{tabular}{|c|c|c|c|c|c|c|c|c|c|c|c|c|}
\hline & \multicolumn{3}{|c|}{ Toll highways $(2 \times 2 / 3$ lanes $)$} & \multicolumn{3}{|c|}{ Free highways $(2 \times 2 / 3$ lanes $)$} & \multicolumn{3}{|c|}{ National roads $(2 \times 1$ lanes $)$} & \multicolumn{3}{|c|}{1 st order regional $(2 \times 1$ lanes $)$} \\
\hline & 1980 & 2007 & $\Delta \%$ & 1980 & 2007 & $\Delta \%$ & 1980 & 2007 & $\Delta \%$ & 1980 & 2007 & $\Delta \%$ \\
\hline Number & 386 & 675 & 74.9 & 134 & 2430 & 1713.4 & 5287 & 3946 & -25.4 & 1842 & 1608 & -12.7 \\
\hline \multirow[t]{3}{*}{ Dis. $(\mathrm{km})$} & 1630 & 2883 & 76.9 & 335 & 9557 & 2752.8 & 21,456 & 16,372 & -23.7 & 11,703 & 10,714 & -8.5 \\
\hline & \multicolumn{3}{|c|}{ 2nd order regional } & \multicolumn{3}{|c|}{ Secondary roads } & \multicolumn{3}{|c|}{ Local roads } & \multicolumn{3}{|c|}{ All roads } \\
\hline & 1980 & 2007 & $\Delta \%$ & 1980 & 2007 & $\Delta \%$ & 1980 & 2007 & $\Delta \%$ & 1980 & 2007 & $\Delta \%$ \\
\hline Number & 3792 & 3648 & -3.8 & 1973 & 1940 & --1.7 & 761 & 742 & -2.5 & 14,175 & 14,989 & 5.7 \\
\hline Dis. (km) & 27597 & 27161 & -1.6 & 19,059 & 18,943 & -0.6 & 1274 & 1217 & -4.5 & 83,055 & 86,849 & 4.6 \\
\hline
\end{tabular}

Each one of these networks has a cartographic base and a related database. Each link of the network is one arc, $a$, with its corresponding set of attributes in period $t, \mathbf{x}_{a}^{t}$. The database assigns to each arc both the physical and legal characteristic already discussed in the methodological section. For a particular itinerary, total costs are calculated by multiplying the unit distance costs associated to distance and time, by the length of the arcs and the time it takes to cover them, and allowing for the aforementioned provincial differences. 678 transport zones covering the whole territory of mainland Spain were considered for the resolution of the origins and destinations of the minimal economic cost routes-including internal travel costs. ${ }^{8}$ In this stage of the GIS implementation, other ancillary costs were added in the calculation of the routes ${ }^{9}$.

\subsection{GTCs levels and variations}

In this section we present the calculations of GTCs and their variations between 1980 and 2007, as well as their decomposition into the infrastructure and economic components as presented in Eq. (9) for consecutive periods, and Eq. (10) for cumulative variations. To average the generalized transport costs of a particular zone $i$ against the remaining $j$ zones, we depart from the common practice which uses the arithmetic mean $\overline{G T C}_{i j}^{t, t}=1 /(N-1) \sum_{j=1}^{N-1} G T C_{i j, z}^{t, t}$ and does not take account of actual trade between zones, in favour of a weighted approach that multiplies the individual $i, j$ transportation cost by zone $j$ 's share of zone $i$ 's total exports. As a result, our aggregate makes allowances for trade patterns between regions, i.e., the GTC between region $i$ and $j$ is irrelevant in the weighted average cost if these regions do not trade with each other. Here we use the interregional trade database $C$-intereg that provides information on exported and imported goods between provinces in Spain. The data we use correspond to the volume of exported goods (tons) in 2005 classified at the divisional level (NACE Rev.1.1 classification), which are mainly distributed by road freight transportation. The exports at the provincial level have been allocated to the transport zones within a province using as weights the distribution of income-a proxy of the distribution of economic activity driving the exports (see Llano et al., 2010, for a thoughtful discussion of this database and the interregional trade data). Denoting by $X_{i}$ the total volume of road shipping from zone $i$ and by $x_{i j}$ the volume reaching zone $j$, the trade-weighted average of the GTCs corresponds to:

$$
\widehat{G T C}_{i j}^{t, t}=\sum_{j=1}^{N-1} s_{i j}^{05} G T C_{i j, z}^{t, t}=\sum_{j=1}^{N-1}\left(X_{i j}^{05} / X_{i}^{05}\right) G T C_{i j, z}^{t, t}
$$

Table 3 presents the arithmetic average and trade-weighted average of GTCs in Spain aggregated at the regional (NUTS 2) level. The first notable feature of our results is that weighting the GTC by trade data leads to a drastic reduction in GTCs, since most of the exports are to nearby locations whose bilateral GTCs are much lower. In 1980 and 2007, trade-weighted GTCs ( $152.9 €$ and $128.0 €$, respectively) represent about $20 \%$ of their unweighted GTC counterparts (698.9€ and 559.6€). At the highest possible level of territorial disaggregation, Figs. 1a and 1b show the GTC results for the 678 transport zones considering the arithmetic and trade-weighted average of GTCs. In the former case a clear centre-periphery pattern can be seen, with the lowest GTCs located in the centre of Spain and the highest GTCs in the farthest coastal areas. This confirms long-established ideas in the literature on transport accessibility, and reproduces the results obtained for other countries such as France (Combes and Lafourcade, 2005), as well as at the European level (Spiekermann and Nuebauer, 2002). This clear centre-periphery pattern is driven by the fact that only domestic flows were considered. A fuzzier picture can be seen in the two lower maps which show the trade-weighted average of GTCs. In this case, GTCs are strongly influenced by the scope of the commercial flows. However, even in the case of trade-weighted GTCs the highest percentage difference can be found also between central and peripheral regions. Taking 2007 as reference, Madrid presents the lowest value of

\footnotetext{
${ }^{8}$ Internal travel cost depends on the size of the transport zone as well as on its development level (urban or rural), which determines the mean speed of each zone. Internal speeds were linearly fitted, assigning $20 \mathrm{~km} / \mathrm{h}$ to the zone with the highest population density and $80 \mathrm{~km} / \mathrm{h}$ to the zone with the lowest population density. Then, internal $\mathrm{km}$ and travel times were converted to economic values given the corresponding provincial costs. Finally, to estimate the internal $\mathrm{km}\left(D_{i i}\right)$ of zone $i$ we use the method proposed by Rich (1975): $D_{i i}=1 / 2 \sqrt{\text { area } / \pi}$.

${ }^{9}$ E.g., regulated stops for drivers were set by the European Parliament and Council on 15 March, 2006 ((EC) no. 561/2006). The regulation states that the driver must rest $45 \mathrm{~min}$ after $4 \mathrm{~h}$ driving and $11 \mathrm{~h}$ after $9 \mathrm{~h}$.
} 
Table 3

GTCs in the Spanish regions, 1980-2007. Source: Authors' compilation.

\begin{tabular}{|c|c|c|c|c|c|c|}
\hline & \multicolumn{3}{|c|}{ Arithmetic average: $\overline{G T C}_{i j}^{t t}$} & \multicolumn{3}{|c|}{ Trade-weighted average: $\widehat{G T C}_{i j}^{t, t}$} \\
\hline & \multicolumn{2}{|l|}{ Levels (Euros) } & \multirow{2}{*}{$\begin{array}{l}\text { Variation } \\
\Delta \Delta 07 / 80\end{array}$} & \multicolumn{2}{|l|}{ Levels (Euros) } & \multirow{2}{*}{$\begin{array}{l}\text { Variation } \\
\Delta 07 / 80\end{array}$} \\
\hline & 1980 & 2007 & & 1980 & 2007 & \\
\hline Andalusia & 786.8 & 630.5 & -19.9 & 146.01 & 120.17 & -17.70 \\
\hline Aragón & 610.4 & 514.6 & -15.7 & 176.38 & 157.49 & -10.71 \\
\hline Asturias & 1007.2 & 808.8 & -19.7 & 199.00 & 162.84 & -18.17 \\
\hline Cantabria & 836.4 & 639.9 & -23.5 & 185.96 & 139.02 & -25.24 \\
\hline Castilla y León & 543.6 & 422.8 & -22.2 & 146.41 & 121.25 & -17.18 \\
\hline Castilla-La Mancha & 470.3 & 378.6 & -19.5 & 156.09 & 133.41 & -14.53 \\
\hline Catalonia & 918.3 & 780.1 & -15.0 & 143.99 & 126.75 & -11.98 \\
\hline Com. Valenciana & 621.1 & 500.3 & -19.4 & 114.05 & 97.92 & -14.15 \\
\hline Extremadura & 614.6 & 480.1 & -21.9 & 173.20 & 144.35 & -16.65 \\
\hline Galicia & 1052.6 & 791.4 & -24.8 & 190.56 & 148.41 & -22.12 \\
\hline Madrid & 433.7 & 348.7 & -19.6 & 89.81 & 74.94 & -16.56 \\
\hline Murcia & 712.9 & 532.9 & -25.2 & 142.31 & 113.48 & -20.26 \\
\hline Navarra & 654.4 & 552.6 & -15.6 & 142.39 & 123.48 & -13.28 \\
\hline Basque Country & 780.2 & 626.9 & -19.6 & 159.65 & 132.70 & -16.88 \\
\hline La Rioja & 518.2 & 503.2 & -2.9 & 126.99 & 129.08 & 1.64 \\
\hline Mean & 698.9 & 559.6 & -19.9 & 152.93 & 128.00 & -16.30 \\
\hline Maximum & 1052.6 Galicia & 808.8 Asturias & -25.2 Murcia & 199.0 Asturias & 162.8 Asturias & -25.2 Cantabria \\
\hline Minimum & 433.7 Madrid & 348.7 Madrid & -2.9 La Rioja & 89.8 Madrid & 74.9 Madrid & 1.6 La Rioja \\
\hline
\end{tabular}
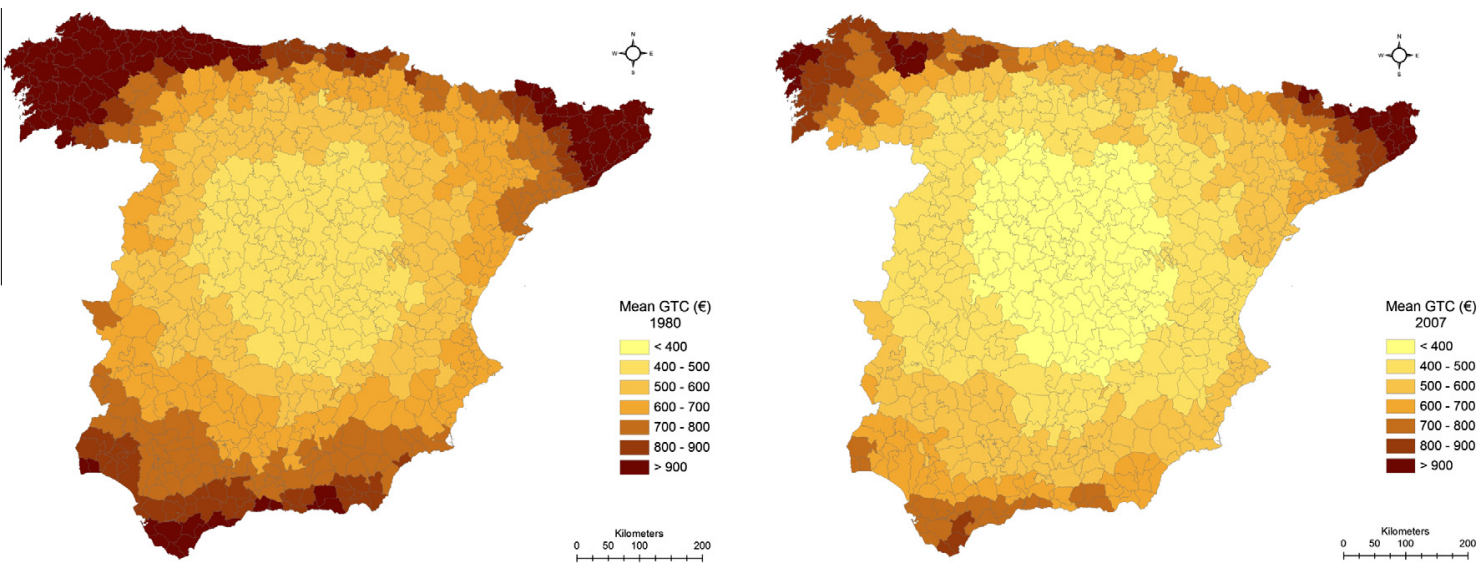

Fig. 1a. Arithmetic average: $\overline{G T C}_{i j}^{t t}, 1980$ versus $2007(€)$. Source: Author's compilation.
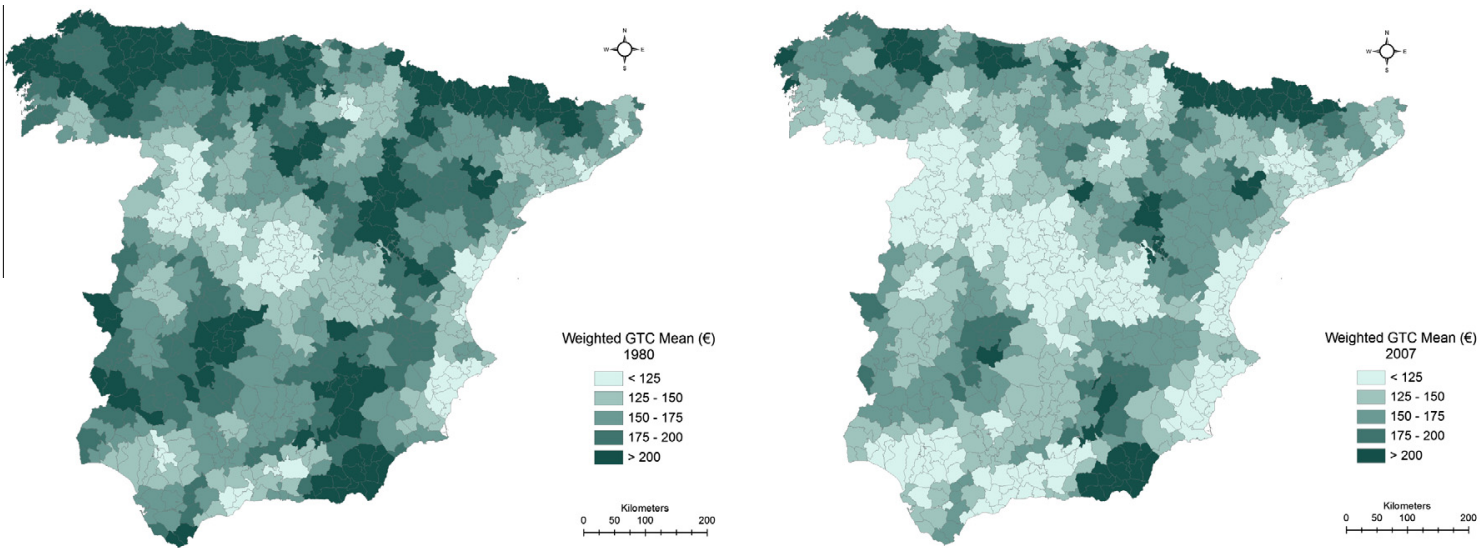

Fig. 1b. Trade weighted average: $\widehat{G T C}_{i j}^{t, t}, 1980$ versus $2007(€)$ Source: Authors' compilation. 
$\Delta \widehat{G T C}_{i j}^{t, t}$. Shift-share analysis, 1980-2007. Source: Authors' compilation.

\begin{tabular}{|c|c|c|c|c|c|c|c|}
\hline & \multicolumn{3}{|c|}{ Levels (Euros) } & \multicolumn{2}{|c|}{ Share in total costs (\%) } & \multicolumn{2}{|l|}{$\Delta \widehat{G T C}_{i j}^{80,07}$} \\
\hline & $\begin{array}{l}1980 \\
(1)\end{array}$ & $\begin{array}{l}2007 \\
(2)\end{array}$ & $\begin{array}{l}\Delta 07 / 80 \\
(3)\end{array}$ & $\begin{array}{l}1980 \\
(4)\end{array}$ & $\begin{array}{l}2007 \\
(5)\end{array}$ & $\%(6)=(3) \cdot(4)$ & $(7)$ \\
\hline Direct costs & 140.97 & 117.84 & -16.41 & 0.92 & 0.92 & -15.12 & 92.80 \\
\hline Distance costs & 70.61 & 66.25 & -6.18 & 0.46 & 0.52 & -2.85 & 17.50 \\
\hline Fuel & 33.66 & 38.66 & 14.86 & 0.22 & 0.30 & 3.27 & -20.04 \\
\hline Accom.\&allow. & 19.47 & 14.41 & -26.00 & 0.13 & 0.11 & -3.32 & 20.31 \\
\hline Tire & 11.38 & 6.75 & -40.68 & 0.07 & 0.05 & -3.05 & -18.75 \\
\hline Maint.\&repair. & 5.74 & 5.82 & 1.35 & 0.04 & 0.05 & 0.05 & -0.31 \\
\hline Toll & 0.35 & 0.60 & 71.53 & 0.00 & 0.00 & 0.17 & -1.01 \\
\hline Time costs & 70.36 & 51.59 & -26.67 & 0.46 & 0.40 & -12.27 & 75.30 \\
\hline Capital & 24.99 & 17.24 & -31.00 & 0.16 & 0.13 & -5.06 & 31.08 \\
\hline Amortization & 17.37 & 14.36 & -17.32 & 0.11 & 0.11 & -1.97 & 12.06 \\
\hline Financing & 7.62 & 2.88 & -62.19 & 0.05 & 0.02 & -3.10 & 19.00 \\
\hline Operating & 45.37 & 34.35 & -24.29 & 0.30 & 0.27 & -7.21 & 44.22 \\
\hline Labour & 31.02 & 26.73 & -13.83 & 0.20 & 0.21 & -2.80 & 17.17 \\
\hline Insurance & 13.45 & 6.68 & -50.35 & 0.09 & 0.05 & -4.42 & 27.15 \\
\hline Taxes & 0.90 & 0.94 & 4.39 & 0.01 & 0.01 & 0.03 & -0.16 \\
\hline Indirect costs & 11.96 & 10.16 & -15.00 & 0.08 & 0.08 & -1.17 & 7.17 \\
\hline Economic costs & 152.93 & 128.00 & -16.30 & 1.00 & 1.00 & -16.30 & 100.00 \\
\hline
\end{tabular}

$74.9 €$ and Asturias the highest value of $162.8 €$ (a 117.4\% difference that does not increase much for the unweighted arithmetic mean with a $131.9 \%$ range). As a result the second feature worth remarking is the large difference observed in GTCs levels.

Focusing now on the variation in generalized transport costs, both the mean of unweighted and trade-weighted GTCs decreased during these three decades, when they fell by -19.9 and $-16.3 \%$, respectively. As in the case of reference economic costs, the fall has not been equal across regions and provinces. In the case of trade-weighted GTCs, Cantabria ( $-25.2 \%)$, Galicia $(-22.1 \%)$ and Murcia $(-20.3 \%)$ have undergone the greatest reductions. At the other extreme, La Rioja is the only region experiencing an increase in its GTC. Other regions such as Aragon ( $-10.7 \%)$, Catalonia $(-12.0 \%)$ and Navarre $(-13.3 \%)$ have also experienced lower reductions in their GTCs. At a provincial level, the reduction in GTCs also shows major differences, even among GTCs belonging to the same region (particularly when a region includes provinces that are far removed from each other and separated by geographical barriers).

\subsection{A shift-share economic decomposition of the sources of GTC decline}

We perform a shift-share analysis of GTC variations that allows us to determine the joint contribution made by all the economic and infrastructure factors to the $-16.3 \%$ reduction in GTCs, through the changes in each individual cost component. Columns 1 and 2 in Table 4 present the direct distance and time costs as well as the indirect costs resulting in the overall reduction in GTCs. The shift-share analysis yields the contribution that each cost makes to the overall GTC decline by weighting its individual shift (column 3) by its base 1980 share (column 4), which can be expressed as a percentage of the overall change (last two columns 6 and 7). The reasons underlying these figures closely follow the patterns and explanations behind each individual trend in the reference unit economic costs already discussed in Section 3.1, Table 1. It can be seen that the fall in GTCs is driven by time costs, with a $75.3 \%$ contribution to the overall reduction $(-12.2 \%$ out of $-16.3 \%)$. Both capital and operating costs contribute to a similar degree $(-5.1 \%$ and $-7.2 \%$, respectively); while insurance costs, followed by financing costs are the components showing the greatest reductions. Distance costs contribute merely $17.5 \%$ to the overall reduction ( $-2.8 \%$ out of $-16.3 \%$ ) with fuel costs counterbalancing the decline in GTCs by $20.0 \%$ (3.3\% increase versus the $-16.3 \%$ reduction in GTC). These are sensible results since the improvement in the road networks results mainly in greater time savings rather than distance savings, and it is therefore the costs associated to the former that drives reductions in GTC. We highlight here that in a standard shift-share analysis of the index $\Delta \widehat{G T C}_{i j}^{80,07}$ the improvements in the network are embedded in each cost change and their effect cannot be disentangled. ${ }^{10}$

\subsection{Decomposing GTCs using index numbers: economic and infrastructure components}

We now decompose the variations in the trade-weighted average of generalized transport costs $\Delta \widehat{G T C}_{i j}^{0, t}$ to identify the individual sources behind their reduction in terms of transport economic costs and infrastructure accessibility variables. We recall the decomposition introduced in the methodological section regarding the Laspeyres-Konüs and Paasche-Konüs cost of producing price indices and their corresponding implicit quantity indices, their geometric mean-Fisher-type-

\footnotetext{
${ }^{10}$ This is confirmed by the reductions observed in the optimal distances and times associated to the minimum cost itineraries: $\Delta d_{i j}^{t, t^{*}}$ and $\Delta t_{i j}^{t, t^{*}}$. From 1985 to 2007 optimal time was reduced by $-14.9 \%$, while optimal distance was reduced by $-0.3 \%$.
} 
Table 5

Decomposition of the fixed base $\Delta \widehat{G T C}_{i j}^{0, t}$ into economic and infrastructure components. Source: Authors' compilation.

\begin{tabular}{|c|c|c|c|c|c|c|}
\hline & \multicolumn{3}{|c|}{ Fixed based indices } & \multicolumn{3}{|c|}{ Percentage variation (\%) } \\
\hline & $\widehat{\Delta \widehat{G T C}_{i j}^{80, t}}$ & $\widehat{E C}_{i j}^{80, t}$ & $\widehat{\mathrm{GTC}_{i j}^{80, t}}$ & $\widehat{\Delta \widehat{G T C}_{i j}^{80, t}}$ & $\widehat{E C}_{i j}^{80, t}$ & $\widehat{I C}_{i j}^{80, t}$ \\
\hline $85 / 80$ & 1.0296 & 1.0387 & 0.9912 & 2.96 & 3.87 & 0.88 \\
\hline $90 / 80$ & 0.9729 & 1.0084 & 0.9648 & 2.71 & 0.84 & 3.52 \\
\hline $95 / 80$ & 0.8896 & 0.9363 & 0.9501 & 11.04 & 6.37 & 4.99 \\
\hline $00 / 80$ & 0.8921 & 0.9597 & 0.9295 & 10.79 & 4.03 & 7.05 \\
\hline $05 / 80$ & 0.8462 & 0.9339 & 0.9062 & -15.38 & 6.61 & 9.38 \\
\hline $07 / 80$ & $\begin{array}{l}\Delta \widehat{G T C}_{i j}^{80,07} \\
0.8370\end{array}$ & $\begin{array}{l}\widehat{E C}_{i j}^{80,07} \\
0.9304\end{array}$ & $\begin{array}{l}\widehat{I C}_{i j}^{80,07} \\
0.8996\end{array}$ & $\begin{array}{l}\Delta \widehat{G T C}_{i j}^{80,07} \\
16.30\end{array}$ & $\begin{array}{l}\widehat{E C}_{i j}^{80,07} \\
6.96\end{array}$ & $\begin{array}{l}\widehat{I C}_{i j}^{80,07} \\
10.04\end{array}$ \\
\hline
\end{tabular}

decomposition given in Eq. (9), as well as their fixed base and interperiodical cumulative versions: Eqs. (10)-(12), respectively. Table 5 shows these results regarding the relative contribution made by the change in economic costs $\widehat{E C}_{i j}^{0, t}$ and the infrastructure accessibility variables $\widehat{I}_{i j}^{0, t}$ to the reduction in GTCs.

For the overall period between 1980 and 2007, about two thirds of the reduction in GTCs is the result of improvements in the network infrastructure, as described in Section 3.1 (with an accumulated percentage reduction of 10.0\%), which have resulted in shorter distances and travel times. The remaining $7.0 \%$ corresponds to the relative deflation of constant economic costs which we have analysed and discussed also in Section 3.1. Thus, the role of infrastructure in GTC reduction is much greater than the role played by the reduction of economic costs. This result is hardly surprising in the Spanish case, since it was in this period that the central and regional governments, making use of major European development programs such as the structural and cohesion funds (e.g., ERDF), invested most heavily in the expansion and improvement of the high-capacity road network. ${ }^{11}$ We can also consistently study the accumulated change in GTCs and their economic and infrastructure components in periods of five years. Table 5 shows that the decrease in GTCs driven by infrastructure reductions is monotonic, as it is constantly reduced in a cumulative way. However, the inflationary trends affecting fuel and labour costs as a result of the oil crisis and the indexation of salaries to the consumer price index (increasing on average about $10 \%$ a year in the 1980 s), ${ }^{12}$ explain why the increase in the price index offsets the reduction in the infrastructure quantity index, resulting in a $3.0 \%$ increase in GTCs between 1980 and 1985. Although in the following five years the economic index still signals an inflationary process of $0.8 \%$ with respect to the base year, the fall in its infrastructure counterpart (3.5\%) offsets this increment, thereby resulting in a 2.7\% reduction in GTCs. From 1990 onwards both the economic and infrastructure indices follow the same reducing trends (for the 1990/1980 period the situation even reverses and the accumulated economic index falls by a greater percentage than the infrastructure index (6.4\% vs. $5.0 \%){ }^{13}$

Finally, using the transitivity property we can complete our study of the reduction in GTCs by calculating their periodical changes-Eq. (12). Table 6 shows the change that takes place as the base period is updated every five years. Here we can identify the third period between 1990 and 1995 as the one where the contribution of the economic index is the greatest (7.15\%). In this period the price of fuel underwent mild increases and inflation levels dropped sharply, thereby containing

\footnotetext{
11 The approach followed by Combes and Lafourcade (2005) to identify the sources of GTCs reduction relies on the calculation of the Laspeyres (producer) price index for transport costs $E C_{i j, c}^{L}$ that assumes that the optimal itineraries do not change over the whole period (i.e., average optimal distance and time remain constant). Expressing in percentage the variation of the arithmetic mean of the generalized transport costs $\Delta \overline{G T C}_{i j, c}^{0, T}(\%)$ and that of the economic costs $\overline{E C}_{i j, c}^{L}(\%)$, they calculate the contribution of infrastructure as a residual: $\overline{I C}_{i j, c}(\%)=\Delta \overline{G T C}_{i j, c}^{0, T}(\%)-\overline{E C}_{i j, c}^{L}(\%)$. We have performed equivalent calculations to determine the bias that this simplification causes on the economic index and, by extension, the associated infrastructure index. Particularly, we calculate the standard Laspeyres price index $\widehat{E C}_{i j, c}^{L}$ and compare it to the true Laspeyres-Konüs price index $\widehat{E C}_{i j, c}^{0}-\mathrm{Eq}$. (5). For the whole period the bias in economic costs is $\widehat{B E}_{i j, c}=\widehat{E C}_{i j, c}^{0}-\widehat{E C}_{i j, c}^{L}=0.9299-0.9336=-0.0037$ or -0.37 percentage points. As a result the contribution of economic costs to GTCs decline using the Laspeyres formulation is lower than the true one by an amount that can be related to the true index: $\widehat{B E}_{i j, c}(\%)=\widehat{E C}_{i j, c}^{0}=-0.37 /-7.01=5.3 \%$. Also, using $(7)$ we can determine the corresponding bias in the Paasche-Konüs implicit quantity index resulting in an overstatement of the contribution of infrastructure by $\widehat{B I}_{i j, c}=\widehat{I C}_{i j, c}^{1}-\widehat{I C}_{i j, c}=0.9901-0.8966=0.0036=0.36$ percentage points, or $3.5 \%$ of the true $\widehat{I C}_{i j, c}^{1}(\%)$. At a NUTS 3 provincial level, the maximum observed economic bias corresponds to Castellón (Comunidad Valenciana) with -1.53 percentage points, resulting in an overestimation of the true contribution of infrastructure to GTC decline by 1.42 percentage points.

${ }^{12}$ The annual rate of change in the CPI over the previous year was $-15.6 \%$ in 1980 and $-6.7 \%$ in 1990 .

${ }^{13}$ We have evaluated if the differences between the three sets of indices are statistically significant. Using alternative non-parametric tests we have tested several complementary null hypotheses relative to: (i) the equality of means ( $t$-test), (ii) the equality of distributions (Wilcoxon signed rank-test), and iii) the independence of the results with regard to their rank (Spearman's correlation test). For the different bilateral relationships: $\Delta \widehat{G T C}_{i j}^{80,07} v s . \widehat{E C}_{i j}^{80,07}, \Delta \widehat{G T C}_{i j}^{80,07} v s$. $\widehat{I C}_{i j}^{80,07}$, and $\widehat{E C}_{i j}^{80,07} v$ s. $\widehat{I C}_{i j}^{80,07}$, the following results are obtained: As for the equality of mean, $t$-tests show that is rejected in all cases with a confidence of $99 \%$. The Wilcoxon test further reinforces this result by indicating that the distributions within the bilateral pairs of results are also statistically different at the same confidence level. Nevertheless, as expected, Spearman's correlation shows that the first two rank the provinces similarly, i.e., GTCs are correlated with their components. However, this is not the case for $\widehat{E C}_{i j}^{80,07}$ and $\widehat{I C}_{i j}^{80,07}$, whose values rank provinces in a different order, therefore suggesting that economic and infrastructure trends exhibit different geographical patterns at aggregate level. This is further investigated in the next section using alternative tests of spatial correlation.
} 
Table 6

Decomposition of interannual $\Delta \widehat{G T C}_{i j}^{t, t+1}$ into economic and infrastructure components. Source: Authors' compilation.

\begin{tabular}{|c|c|c|c|c|c|c|}
\hline & \multicolumn{3}{|c|}{ Interannual indices } & \multicolumn{3}{|c|}{ Percentage variation (\%) } \\
\hline & $\Delta \widehat{G T C}_{i j}^{t, t+n}$ & $\widehat{E C}_{i j}^{t, t+n}$ & $\Delta \widehat{I C}_{i j}^{t, t+n}$ & $\widehat{\Delta G T C}_{i j}^{t, t+n}$ & $\widehat{E C}_{i j}^{t, t+n}$ & $\widehat{I C}_{i j}^{t, t+n}$ \\
\hline $85 / 80$ & 1.0296 & 1.0387 & 0.9912 & 2.96 & 3.87 & 0.88 \\
\hline $90 / 85$ & 0.9449 & 0.9709 & 0.9733 & 5.51 & 2.91 & 2.67 \\
\hline $95 / 90$ & 0.9143 & 0.9285 & 0.9847 & 8.57 & 7.15 & 1.53 \\
\hline $00 / 95$ & 1.0028 & 1.0250 & 0.9783 & 0.28 & 2.50 & 2.17 \\
\hline $05 / 00$ & 0.9486 & 0.9730 & 0.9749 & 5.14 & 2.70 & 2.51 \\
\hline $07 / 05$ & 0.9891 & 0.9963 & 0.9928 & 1.09 & 0.37 & 0.72 \\
\hline
\end{tabular}

salaries. Additionally the reduction in interest rates resulted in lower increases in capital costs, while the rest of the categories followed a similar pattern. Nonetheless, in the subsequent five-year period the situation reversed and economic costs increased by 2.5\%. As expected, this uneven evolution of the economic index cannot be perceived in the periodical infrastructure index, which shows a steady decline over the years, signalling that successive investments in high-capacity roads have contributed steadily to the reduction in GTCs in all periods except the first five years when the modernization of Spanish roads was taking off.

\section{Geographical analyses of GTC variation: spatial association and territorial cohesion}

\subsection{Geographical clusters of GTC variation: market and network effects}

As discussed in Section 3.2, GTCs and their economic and infrastructure indices show large territorial disparities. Examining variation values at the NUTS 3 level we find that in 31 out of the 47 provinces the reduction in the infrastructure index is greater than that of the economic index. The contribution of infrastructure was greater within those peripheral regions whose accessibility to the Iberian peninsula was lowest as a result of physical barriers. In contrast, the provinces located in the centre have profited relatively less from the new infrastructure, and particularly Madrid and the surrounding provinces.

Before we determine whether there are significant clusters in the variations by means of the Moran global and local indicators of spatial association, we analyse particular trends in economic and infrastructure indices following the methodological approach proposed by Camagni and Capellin (1985). The central idea consists of studying the evolution of the variations in GTC by plotting their economic and infrastructure components with respect to the national average. This makes it possible to differentiate four categories of regions: leading provinces where both indices are above the national average, lagging provinces where they are below, economy-driven regions where this component is above but the infrastructure component is not, and infrastructure or accessibility-driven regions where the opposite is observed. All four categories are shown in Fig. 2. Provinces in shaded circles lag behind in both the economic and infrastructure indices, or in only one of them, but still present lower GTC reductions than the national average (represented by the $45^{\circ}$ bisecting line). Conversely, unshaded circles show leading provinces where both indices are below the average-or at least one of the two-but in this case resulting in greater than average GTC reductions. Even with this simple analysis we observe emerging patterns of spatial association, with the four Galician provinces situated in northwest Spain (PON, ACO, OUR, LUG) leading GTC reductions, while all four north-eastern Catalonian provinces (GIR, BAR, LER, TAR) present the lowest GTC reductions.

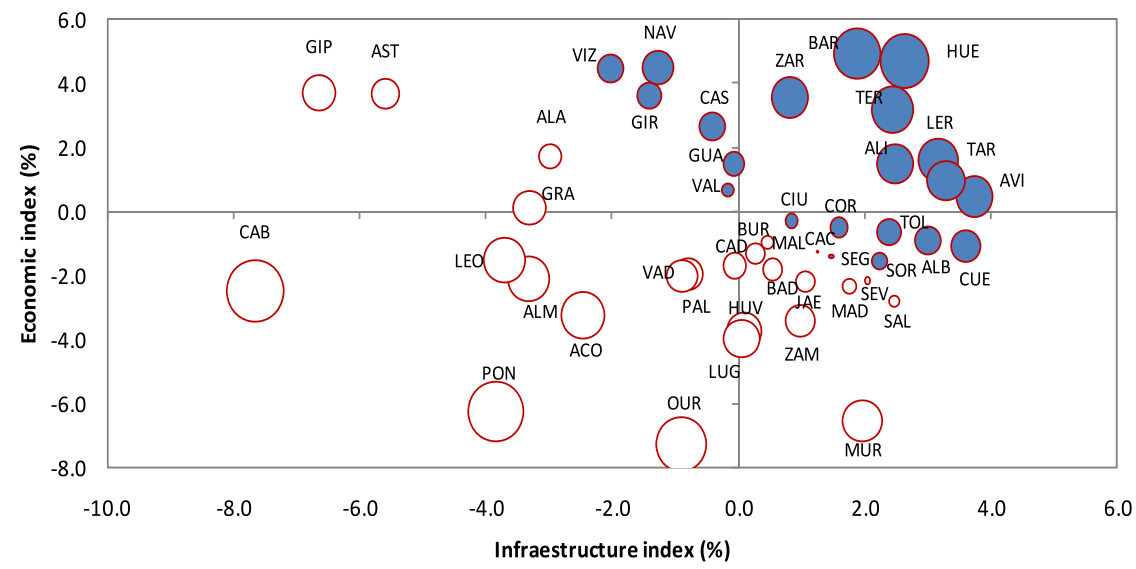

Fig. 2. Economic $\widehat{E C}_{i j}^{80,07}$ and infrastructure $\widehat{I C}_{i j}^{80,07}$ indices (\%). Source: Authors' compilation. 
In principle, a certain degree of spatial clustering of the economic and infrastructure indices should be expected as long as neighbouring provinces present similar evolution in their cost structures and infrastructure endowments. Regarding the economic costs of transportation services, labour expenses will exhibit similar trends in those areas comprised in a single geographical market, and where changes in the industry structure and regulations take place simultaneously. The same would apply to other elements such as accommodation and allowances, maintenance and repairs, tires, etc., where the degree of competition will result in similar pricing rules (e.g., mark-ups), as long as there is effective competition between firms within a geographical range. Since the likelihood of similar trends in economic costs depends on the way in which the specific input markets are integrated across neighbouring locations, as well as on the way in which effective competition and market performance shape similar pricing rules, we associate the presence of spatial clustering in cost trends to the degree of market integration, i.e., the existence of a geographical market effect. In the case of changes in infrastructure endowments, infrastructure investment would make a similar contribution to GTC decline in neighbouring areas provided that an improvement to a given arc of a road network also benefits the remaining elements. In general, this would be the case in radial networks (also referred to as "star" or "hub and spoke") such as the kind existing in Spain in the 1980s, where the peripheral and central regions connected by corridors jointly benefited from improvements in the radial arcs. Here we highlight two points concerning this issue. Firstly, the benefits are normally asymmetrical, since for an outer node the development of its radial connection is critical when increasing its accessibility to the whole network; while for the centre, that particular connection is only one of its multiple radial links. This result is evident in the Spanish case, where reductions in GTC driven by infrastructure improvements are greater in peripheral regions than in central regions-particularly until 1995 when the radial network of high-capacity roads was completed. Secondly, it is normally the case that in radial networks the outer nodes are further conformed by clusters of provinces presenting a subnetwork structure (e.g., in the Spanish case, Galicia, the Basque Country and Catalonia are good examples), while the centre corresponds to a single territory (e.g., the Madrid region itself). These patterns of asymmetrical and contemporary shared benefits from infrastructure improvements are the result of what is termed in the accessibility literature as transportation network effects (van Excel et al., 2002).

To determine whether there is spatial autocorrelation at the aggregate level in GTC variation, as well as in its economic and infrastructure components associated to market and network effects, we have calculated Moran's indicator for all these indices (see Anselin, 1995). This measure allows us to evaluate whether the spatial pattern of the variations is clustered, dispersed, or random. Any statistically significant value of the indicator in the proximity of 1.0 indicates clustering, while a value near -1.0 indicates dispersion. The results reported in Table 7 show positive and significant values, confirming the spatial clustering of the variations. Even if the values corresponding to the variation in economic variables and infrastructure are similar, the greater value of infrastructure suggests that the network effect predominates over the market effect when favouring spatial clustering.

This is further corroborated in Fig. 3a-c, where the values of the local Moran's indicator (Anselin Local Moran's Indicator) are shown. This indicator allows areas to be identified where the spatial clustering is more intense, as suggested in Fig. 3. At a NUTS 3 level, when a province presents a high value of GTC variation, economic costs or infrastructure costs, and it is surrounded by other provinces with similar values, they conform a high-high (HH) spatial cluster. In our case, this implies a lower reduction in GTC and its components, since the higher the value of the indices, the lower their reduction from the base year. Conversely, low-low (LL) pairings signal the existence of significant clusters where GTCs and their components have decreased most. The remaining combinations: HL and LH, would be observed when a province of one of the two types is surrounded by regions of the other type; this situation is unlikely to emerge since it would be indicative of separate geographical markets for the input factors regarding economic costs, and from an infrastructure perspective, the case of isolated provinces that do not benefit from network effects because of geographical barriers.

As regards generalized transport cost variations, $\Delta \widehat{G T C}_{i j}^{80,07}$ (Fig. 3a), there is a cluster of provinces in the northeast-Galicia and León-which exhibit greater reductions (LL) due to both reductions in economic costs $\widehat{E C}_{i j}^{80,07}$, and distance and time infrastructure accessibility variables $\widehat{I C}_{i j}^{80,07}$. Conversely, in the northeast-Catalonia and Aragon-we find a significant cluster of provinces where GTC variation is below the average; this has a HH profile. The source of this latter clustering is the jointly significant increase in economic costs in these neighbouring provinces that prevents a larger decline in generalized transportations costs (Fig. 3b). Interestingly, in Catalonia and Aragon there is no HH pattern for infrastructure, a situation which signals that the benefits from greater accessibilities can be found only in some of the provinces within these regions, and there is therefore no significant spatial cluster of relatively low decreases (HH) in $\widehat{I C}_{i j}^{80,07}$ indices for these provinces (Fig. 3c).

We identify two interesting cases that show the potentiality of the spatial association analysis when identifying clusters in terms of generalized, economic and infrastructure transport costs. The case of the provinces in the Basque Country is noteworthy because we identify two opposite clusters according to economic and infrastructure costs, with an $\mathrm{HH} \widehat{E C}_{i j}^{80,07}$ trend

Table 7

Spatial autocorrelation of variations: Moran's index. Source: Authors' compilation.

\begin{tabular}{lll}
\hline & Moran indicator & $p$-Value \\
\hline$\Delta \widehat{G T C}_{i j}^{80,07}$ & 0.2346 & 0.0000 \\
$\widehat{E C}_{i \dot{0}, 07}^{80,07}$ & 0.2378 & 0.0000 \\
$\widehat{I C}_{i j}^{80,0}$ & 0.2740 & 0.0000 \\
\hline
\end{tabular}


(a)

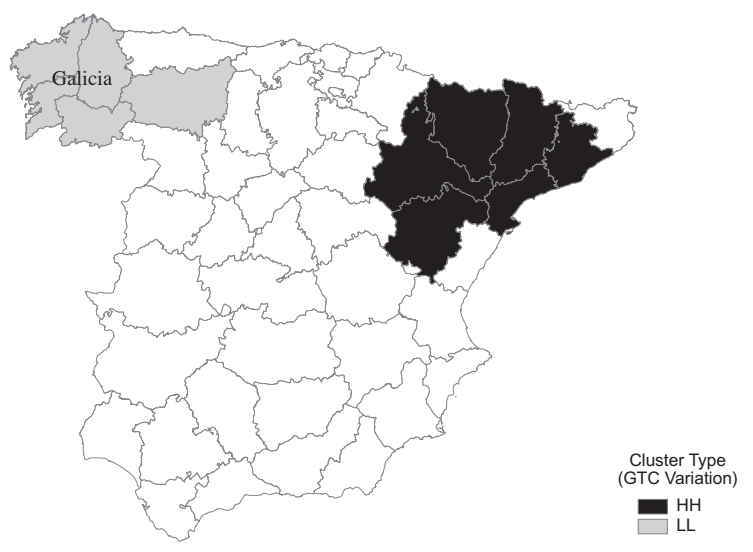

(b)

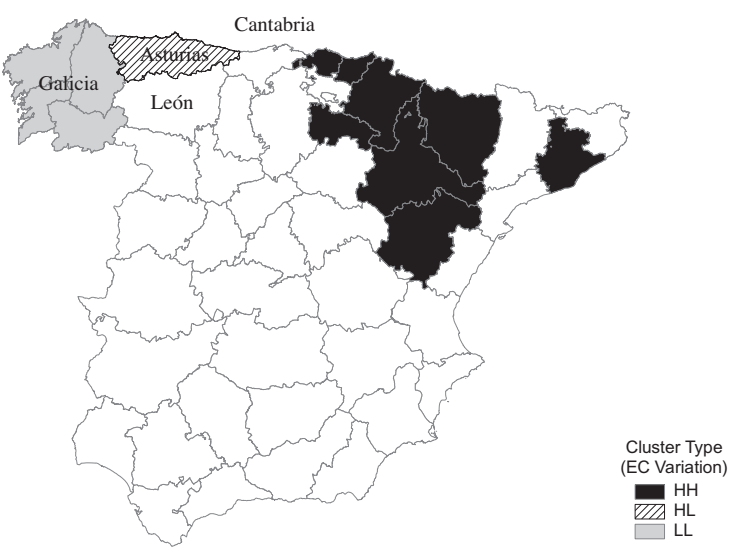

(c)

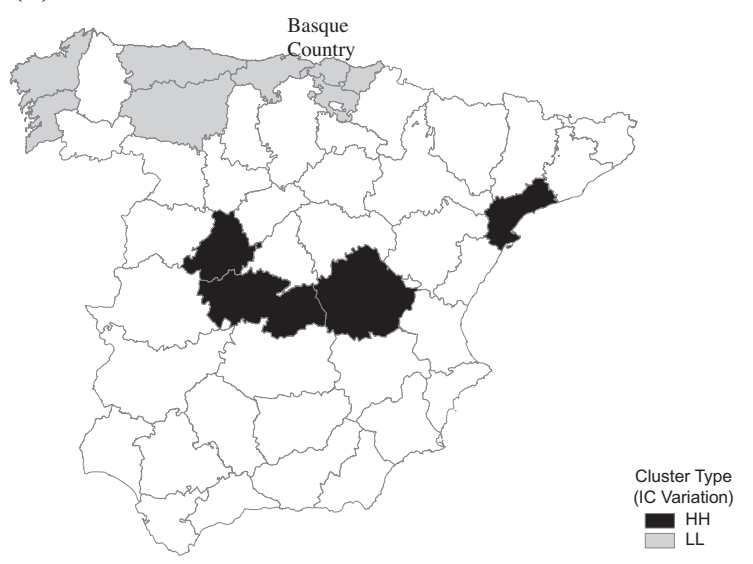

Fig. 3. Spatial clustering: Anselin Local Moran's indicator: (a) $\Delta \widehat{G T C}_{i j}^{80,07}$, (b) $\Delta \widehat{E C}_{i j}^{80,07}$, (c) $\Delta \widehat{I C}_{i j}^{80,07}$. Source: Authors' compilation.

offsetting the LL $\widehat{I C}_{i j}^{80,07}$, so no clustering is observed in terms of the overall aggregate $\Delta \widehat{G T C}_{i j}^{80,07}$. The second case corresponds to the province of Asturias in the northwest, with a significant $\mathrm{HL} \widehat{E C}_{i j}^{80,07}$. This situation emerges because economic costs have decreased to a lesser extent in this province than in the surrounding locations. This disparity is the result of specific market determinants that even result in reversed trends in key economic costs, particularly fuel, salaries, and capital costs.

\subsection{Effects of GTC variation on territorial cohesion}

We conclude our geographical analyses by studying the effects of GTC variations on territorial cohesion using their relative concentration or dispersion around the mean over the different periods. This concept concerns regional convergence or integration, and is becoming an increasingly important issue in European Union countries, particularly since the goal of territorial cohesion was introduced in the EU agenda as an important policy objective (CEC, 2004). The EU defines territorial cohesion as balanced development, with fewer regional disparities, and deems transport policy to be one of the main instruments to improve it, especially insofar as it enhances the accessibility of peripheral regions to central markets. In view of the fact that equal access to markets is one of the main indicators which reflects whether territorial cohesion has been achieved, in this section we analyse the convergence divergence of GTCs as a proxy of changes in regional disparities. In order to do so, we use a set of indicators frequently used in the literature (e.g., Ramjerdi, 2006; López et al., 2008), and particularly the Gini coefficient, the variation coefficient and Theil's index. If the variation in GTCs and their components shows a convergent tendency, then territorial cohesion in terms of accessibility levels has increased.

Table 8 reports these measures of dispersion for the generalized transport cost variation and the reference economic costs and network infrastructure. Particularly, we measure the relative dispersion at the NUTS 3 provincial level using: (i) the trade-weighted version of Eq. (3) $\widehat{G T C}_{i j}^{t, t}$, which allows us to determine whether GTCs themselves have converged over the years; (ii) Eq. (6): $\widehat{G T C}_{i j}^{t, 80}$ measuring the convergence of the GTCs driven by the equalization of the reference unit economic costs, since the infrastructure network is kept constant in the base year and therefore plays no role in GTC variations; and, 
Table 8

Variation in territorial cohesion: $\widehat{G T C}_{i j}^{t, t}, \widehat{G T C}_{i j}^{t, 80}$ and $\widehat{G T C}_{i j}^{80, t}$.

\begin{tabular}{|c|c|c|c|c|c|c|c|}
\hline & & \multicolumn{3}{|c|}{ Inequality measures } & \multicolumn{3}{|c|}{ Variation 1980-2007 (\%) } \\
\hline & & GINI coefficient & Variation coefficient (\%) & $\overline{\text { Theil's index }}$ & GINI coefficient & Variation coefficient (\%) & $\overline{\text { Theil's index }}$ \\
\hline \multirow{7}{*}{$\widehat{G T C}_{i j}^{t, t}$} & 1980 & 0.0703 & 18.38 & 0.0075 & & & \\
\hline & 1985 & 0.0699 & 18.27 & 0.0074 & -0.58 & -0.61 & -1.86 \\
\hline & 1990 & 0.0680 & 17.75 & 0.0071 & 3.28 & -3.40 & -6.27 \\
\hline & 1995 & 0.0705 & 18.49 & 0.0075 & 0.28 & 0.63 & -0.03 \\
\hline & 2000 & 0.0676 & 17.62 & 0.0070 & -3.80 & -4.12 & -6.98 \\
\hline & 2005 & 0.0658 & 17.48 & 0.0069 & -6.38 & -4.88 & -8.47 \\
\hline & 2007 & 0.0653 & 17.35 & 0.0068 & -7.06 & -5.58 & -9.72 \\
\hline \multirow{6}{*}{$\widehat{G T C}_{i j}^{t, 80}$} & 1985 & 0.0705 & 18.44 & 0.0075 & 0.27 & 0.32 & -0.21 \\
\hline & 1990 & 0.0683 & 17.79 & 0.0071 & -2.77 & -3.20 & -5.80 \\
\hline & 1995 & 0.0698 & 18.12 & 0.0073 & -0.75 & -1.43 & -2.33 \\
\hline & 2000 & 0.0700 & 18.19 & 0.0074 & -0.45 & -1.02 & -1.06 \\
\hline & 2005 & 0.0698 & 18.32 & 0.0076 & -0.71 & -0.33 & 0.37 \\
\hline & 2007 & 0.0692 & 18.14 & 0.0074 & -1.55 & -1.29 & -1.07 \\
\hline \multirow[t]{6}{*}{$\widehat{G T C_{i j}^{80, t}}$} & 1985 & 0.0695 & 18.19 & 0.0074 & -1.04 & -1.03 & -1.80 \\
\hline & 1990 & 0.0699 & 18.32 & 0.0075 & -0.53 & -0.31 & -0.77 \\
\hline & 1995 & 0.0711 & 18.90 & 0.0078 & 1.21 & -2.81 & 3.31 \\
\hline & 2000 & 0.0680 & 17.82 & 0.0071 & -3.24 & -3.02 & -5.89 \\
\hline & 2005 & 0.0672 & 17.57 & 0.0069 & -4.40 & -4.38 & -8.35 \\
\hline & 2007 & 0.0674 & 17.56 & 0.0069 & -4.11 & -4.45 & -8.70 \\
\hline
\end{tabular}

finally, (iii) the counterpart to Eq. (6): $\widehat{G T C}_{i j}^{80, t}$, measuring whether GTCs have converged due to the equalization of the accessibility variables of distance and time brought about by improvements in the road infrastructure, since the unit economic costs remain constant in the same base year. All three measures indicate an overall reduction in regional disparities in terms of accessibility to markets, and therefore an increase in territorial cohesion. Considering the reductions in disparities regarding the reference unit economic costs $\widehat{G T C}_{i j}^{t, 80}$, and the accessibility variables associated to the infrastructure $\widehat{G T C}_{i j}^{80, t}$, the latter shows greater convergence with a reduction in disparities of $4.1 \%$ in the Gini coefficient, while the former is reduced by $1.5 \%$. This result is fairly robust, since it holds independently of the dispersion measure used.

Consequently, this analysis confirms that the main driver behind the reduction in territorial disparities in terms of GTCs is the infrastructure investment policy implemented by the Spanish central and regional governments, particularly in the 1995-2007 period. The fact that the greatest reduction in disparities took place in this period instead of 1980-1995 is because in this earlier period, all major road investment projects were devoted to improving the radial connections between the periphery and the centre of the Peninsula, while in the latter period, investments reinforced the grid nature of the transport network, which benefits peripheral areas more than central areas. Nor is it surprising that economic costs were less relevant when driving transport cost down, since aside from significant technological improvements (in the reference vehicle, logistics, etc.), other political actions determining market conditions such as measures designed to liberalize and deregulate labour and capital markets have not been as successful as their infrastructure counterparts.

We can therefore conclude that transport infrastructure as a regional policy instrument has proved successful in reducing accessibility disparities in Spanish provinces, and that this reduction in the distance and time variables has also brought about fewer disparities in GTCs. It is beyond the scope of this paper to study the consequences of this reduction in GTCs in terms of the location of economic activity, but it is a well-known fact that within countries themselves, regional disparities throughout this period in per capita GDP have not decreased in Europe- including Spain, see Duro (2004). Therefore, the generally accepted notion of higher road infrastructure investment bringing greater regional cohesion-as studied for the Italian case by Faini (1983) - would not be supported in the Spanish case, and this in turn corroborates the main proposition emanating from new economic geography models-namely that reducing transport costs may favour core-periphery patterns-, and warns against indiscriminate infrastructure investments that could result in greater disparities (Ottaviano, 2008).

\section{Conclusions}

In this study we introduce index number methods to improve our understanding of the changes in generalized transport costs and their economic (price) and infrastructure (quantity) determinants. The former is related to the reference unit economic costs, while the latter corresponds to distance and time accessibility determinants. Given its desirable axiomatic and theoretical properties, we decided on a fixed-based version of GTC variations which satisfies the transitivity property or circularity test, and where each one of the two mutually exclusive economic and infrastructure components corresponds to the Fisher formulation. From an empirical perspective we illustrate our proposed methodology by calculating the GTCs for road freight transportation in Spain for five-year periods between 1980 and 2007. Our results show that trade-weighted GTCs declined by $-16.3 \%$ from 1980 to 2007, and using the index number methodology we learn that the main driver behind this fall is the contribution made by infrastructure improvements in the form of time and distance reductions. In terms of var- 
iation rates, the reduction in GTCs associated to infrastructure accounts for about two thirds of the overall GTC decline, $10.0 \%$, with the reduction in economic costs accounting for the rest. From a time perspective, GTC reductions are more intense in the 1990-1995 and 2000-2005 periods. In these years the steady improvements in road infrastructure, generally observed throughout the whole period, are reinforced by the fall in the reference economic costs, both sources which contribute to greater GTC reductions.

We find a large geographical heterogeneity in both GTC levels and their variations, particularly for arithmetically averaged GTCs. In this case, the usual centre-periphery pattern favours Madrid as the region with the lowest GTCs thanks to its central location and high capacity road network. The picture is not so clear when considering trade-weighted GTCs, since commercial flows are clearly constrained by many factors such as the transport costs themselves, but also by the economic specialization of regions in sectors producing goods with high weight-to-value ratios and which are prone to trade by road transportation (e.g., manufactures) -as studied by Duranton et al. (2013). However, using different global and local indicators of spatial correlation we are able to identify relevant clusters where variation in GTCs and their components exhibit a significant geographical association. Particularly, the values of the local Moran's index not only indicate significant clustering of GTC variations in northeast and northwest Spain-with GTCs falling below and above the national average, respectively-but also considerable market effects where the trends in economic costs correlate in neighbouring regions, as well as significant network effects where the improvements in the road infrastructure translate into distance and time reductions that also correlate in space.

Finally, we study whether GTCs and their components converge or diverge over time, so as to draw relevant implications from the perspective of transportation policy. Using several measures of dispersion we find a robust convergence process in GTCs accompanying their 16.3\% decrease. This leads to the conclusion that the transportation policies implemented in Spain between 1980 and 2007 have contributed to the overall reduction in regional disparities in terms of accessibility to markets, and therefore to an increase in territorial cohesion. In this sense we can differentiate between (i) economic policy measures resulting in lower economic costs such as deregulation initiatives bringing more flexible and competitive labour and capital markets (e.g., reforming labour contracts or the adoption of the Euro, respectively)-, and (ii) project-specific investment decisions conforming the infrastructure policy, aimed at improving the road network. It could be argued that both types of policies have resulted in a reduction in regional disparities. However, since the evolution of economic costs not only depends on the actions undertaken by the governing administrations but also primarily on global market forces (e.g., fuel costs depending on oil prices)-whereas investment decisions are taken almost exclusively at a political level-we can confirm that infrastructure policies have had a larger effect on GTCs than economic policies. In the light of these results we conclude that transportation policy both at the economic and infrastructure levels, whose effects on GTCs can be associated precisely to the changes in these particular components, have proved successful in driving down the cost of transportation in Spain. Since the departure point of Spain in the base year of 1980 corresponded to a country where the transport market was still subject to intense regulation, and where networks were relatively underdeveloped in terms of high-capacity roads and connections between peripheral regions, we believe that the Spanish experience can serve as an useful benchmark for planning and designing similar policies in other countries in the same situation, .e.g., as would be the case of Eastern European countries nowadays.

\section{Disclaimer}

The views expressed are purely those of the writer and may not in any circumstances be regarded as stating an official position of the European Commission.

The authors acknowledge financial support from the Spanish Ministerio de Fomento and Madrid's Directorate-General of Universities and Research, under project grants DESTINO (42/08) and Transportrade (S2007-HUM-0467).

Anselin, L., 1995. Local indicators of spatial association - LISA. Geogr. Anal. 27 (2), 93-115.

Camagni, R., Capellin, R., 1985. La productivité sectorielle et la politique régionale. European Commission, Brussels.

CEC, 2004. A new Partnership for Cohesion: Convergence, Competitiveness, Cooperation: Third Report on Economic and Social Cohesion. European Commission, Brussels.

Combes, P.P., Lafourcade, M., 2005. Transport costs: measures, determinants, and regional policy implications for France. J. Econ. Geogr. 5 (3), 319-349.

Diewert, E.W., 1993. The economic theory of index numbers: a survey. In: Diewert, E.W., Nakamura, A.O. (Eds.), Essays in Index Number Theory, vol. 1. Elsevier, Amsterdam, pp. 177-207.

Diewert, E.W., 2004. Index Number Theory: Past Progress and Future Challenges. Mimeo, University of British Columbia, Canada, http://www.econ.ubc.ca/ diewert/concepts.pdf.

Dijkstra, E.W., 1959. A note on two problems in connection with graphs. Numer. Math. 1, 269-271.

Duranton, G., Morrow, P.M., Turner, M.A., 2013. Roads and trade: evidence from the US. Rev. Econ. Stud.. http://dx.doi.org/10.1093/restud/rdt039.

Duro, J.A., 2004. Regional Income Inequalities in Europe: An Updated Measurement and Some Decomposition Results. Working Paper 04.11. Department of Applied Economics, Universitat Autonoma of Barcelona, Barcelona.

Faini, R., 1983. Cumulative process of deindustrialization in an open region: the case of southern Italy. J. Dev. Econ. 12 (3), $277-301$.

Fisher, I., 1922. The Making of Index Numbers. Houghton-Mifflin, Boston. 
Fisher, F., Shell, K., 1998. Economic Analysis of Production Price Indexes. Cambridge University Press, Cambridge, UK.

Geurs, K.T., Ritsema van Eck, J.R., 2001. Accessibility Measures: Review and Applications. RIVM Report 408505 006. Urban Research Centre, Utrecht University, Utrecht.

Glaeser, E., Kohlhase, J., 2003. Cities, regions and the decline of transport costs. Papers Reg. Sci. 83 (1), $197-228$.

Hummels, D., 2007. Transportation costs and international trade in the second era of globalization. J. Econ. Perspect. 21 (3), $131-154$.

Hummels, D., Lugovskyy, V., Skiba, A., 2007. The Trade Reducing Effect of Market Power in International Shipping. NBER Working Paper 12914. National Bureau of Economic Research, London.

IMF, 2004. Producer Price Index Manual. Theory and Practice. International Monetary Fund, Washington, DC.

Ivaldi, M., McCullough, G., 2007. Railroad pricing and revenue-to-cost margins in the post-staggers era. In: Dennis, S., Valley, W. (Eds.), Research in Transportation Economics. Elsevier, Amsterdam.

Konüs, A.A., 1924. The problem of the true index of the cost of living. Translated in Econometrica 7 (1939), 10-29.

Laspeyres, E., 1871. Die Berechnung einer mittleren waarenpreissteigerung. Jahrbücher für Nationalökonomie und Statistik 16, $296-314$.

Llano, C., Esteban, A., Pulido, A., Pérez, J., 2010. Opening the interregional trade black box: the c-intereg database for the Spanish economy (1995-2005). Int. Reg. Sci. Rev. 33 (3), 302-337.

López, E., Gutiérrez, J., Gómez, G., 2008. Measuring regional cohesion effects of large-scale transport infrastructure investments: an accessibility approach. Eur. Plann. Stud. 16, 277-301.

Martínez-Zarzoso, I., Nowak-Lehmann, F., 2006. Is distance a good proxy for transport costs? The case of competing transport modes. J. Int. Trade Econ. Develop. 16 (3), 411-434.

MFOM, 2007. Observatorio de costes del transporte de mercancías por carretera. 2007. Ministerio de Fomento, Madrid.

MFOM, 2008. Los transportes, las infraestructuras y los servicios postales en España: Informe Anual 2007. Ministerio de Fomento, Madrid.

Nichols, A.J., 1975. Standard Generalized Cost Parameters for Modelling Interurban Traffic and Evaluating Interurban Road Schemes. Note 255, Mathematical Advisory Unit, Department of the Environment, London.

Ottaviano, G.C., 2008, Infrastructure and economic geography: an overview of theory and evidence. European Investment Bank Paper 13(2). Luxembourg: European Investment Bank.

Oum, T.H., Tretheway, M.W., Waters, W.G., 1992. Concepts, methods, and purposes of productivity measurement in transportation. Transp. Res. Part A 26 (6), 493-505.

Paasche, H., 1874. Über die preisentwicklung der letzten jahre nach den hamburger borsennotirungen. Jahrbücher fur Nationalökonomie und Statistik 12, $168-178$.

Ramjerdi, F., 2006. Equity measures and their performance in transportation- transportation research record. J. Transp. Res. Board 1983, 67-74.

Rich, D., 1975. Accessibility and Economic Activity: A Study of Locational Disadvantage in Scotland. Ph.D. Thesis, University of Cambridge, Cambridge, UK. Spiekermann, K., Nuebauer, J., 2002. European Accessibility and Peripherality: Concepts, models and Indicators. Stockholm, Nordregio.

Teixeira, A.C., 2006. Transport policies in light of new economic geography: The portuguese experience. Regional Science and Urban Economics 36, $450-466$.

Tolofari, S.R., 1986. Open Registry Shipping: A Comparative Study of Costs Freight Rates. Routledge, New York.

van Excel, J., Rienstra, S., Gommers, M., Pearman, A., Tsamboulas, D., 2002. EU involvement in TEN development: network effects and European value added. Transp. Policy 9, 299-311.

World Bank, 2009. Reshaping Economic Geography. World Bank, Washington, DC.

Zofío, J.L., Condeço-Melhorado, A.M., Maroto-Sánchez, A., Gutiérrez, J., 2011. Decomposing Generalized Transport Costs Using Index Numbers: A Geographical Analysis of Economic and Infrastructure Fundamentals. Working Paper \#2011/06. Departamento de Análisis Económico: Teoría Económica e Historia Económica, Universidad Autónoma de Madrid, Spain. 